\title{
The Genetic Control of the Compound Leaf Patterning in Medicago truncatula
}

\author{
Xiaoyu Mo $\mathrm{M}^{1,2+}$, Liangliang He ${ }^{1 * t}$, Ye Liu ${ }^{1,3}$, Dongfa Wang ${ }^{1,3}$, Baolin Zhao ${ }^{1}$ and \\ Jianghua Chen ${ }^{1,2,3 *}$
}

${ }^{1}$ CAS Key Laboratory of Topical Plant Resources and Sustainable Use, CAS Center for Excellence in Molecular Plant Sciences, Xishuangbanna Tropical Botanical Garden, Chinese Academy of Sciences, Kunming, China, ${ }^{2}$ University of Chinese Academy of Sciences, Beijing, China, ${ }^{3}$ School of Life Sciences, University of Science and Technology of China, Hefei, China

\section{OPEN ACCESS}

Edited by:

Yuling Jiao,

Peking University, China

Reviewed by:

Lin Xu,

Center for Excellence in Molecular Plant Sciences, Chinese Academy of Sciences (CAS), China

Ram Kishor Yadav,

Indian Institute of Science Education and Research Mohali, India

*Correspondence: Liangliang $\mathrm{He}$

heliangliang@xtbg.ac.cn Jianghua Chen

jhchen@xtbg.ac.cn

${ }^{t}$ These authors have contributed equally to this work

Specialty section:

This article was submitted to Plant Development and EvoDevo, a section of the journal

Frontiers in Plant Science

Received: 30 July 2021 Accepted: 15 December 2021 Published: 13 January 2022

Citation:

Mo X, He L, Liu Y, Wang D,

Zhao $B$ and Chen J (2022) The Genetic Control of the Compound

Leaf Patterning in Medicago

truncatula.

Front. Plant Sci. 12:749989. doi: 10.3389/fp/s.2021.749989
Simple and compound which are the two basic types of leaves are distinguished by the pattern of the distribution of blades on the petiole. Compared to simple leaves comprising a single blade, compound leaves have multiple blade units and exhibit more complex and diverse patterns of organ organization, and the molecular mechanisms underlying their pattern formation are receiving more and more attention in recent years. Studies in model legume Medicago truncatula have led to an improved understanding of the genetic control of the compound leaf patterning. This review is an attempt to summarize the current knowledge about the compound leaf morphogenesis of $M$. truncatula, with a focus on the molecular mechanisms involved in pattern formation. It also includes some comparisons of the molecular mechanisms between leaf morphogenesis of different model species and offers useful information for the molecular design of legume crops.

Keywords: compound leaf development, morphogenesis, pattern formation, leaflet number and arrangement, Medicago truncatula

\section{INTRODUCTION}

Leaves are the most important photosynthetic organs of plants that produce nutrients, to store, or transport them to other organs. Leaf shape is one of the most diverse morphological features in plant kingdoms, which is the result of the evolutionary adaptation of a species to its specific environment (Warman et al., 2011; Milla, 2012; Schmerler et al., 2012). Two basic types of leaves, simple and compound, are distinguished by the pattern of the distribution of blades on the petiole. Simple leaves have a single undivided blade per petiole. Compound leaves consist of multiple independent blade units, called leaflets, that are attached to the petiole and its derivatives, and organized into specific patterns. Different compound leaves show great variation in a leaf pattern, the leaflet number, and organization, exhibiting much more morphological diversity in nature. Each leaflet is usually considered to be functionally equivalent to a simple leaf, and therefore, the emergence of compound leaves during evolution is thought to have provided some advantages, including increased photosynthetic efficiency and enhanced adaptation to herbivory (Champagne and Sinha, 2004; Warman et al., 2011; Milla, 2012). A major question for plant developmental 
biologists is the molecular mechanism underlying the diversity of compound leaf forms during evolution.

In order to study the molecular basis underlying compound leaf development, five model compound-leafed plants are widely used: the Solanaceae tomato (Solanum lycopersicum), the Brassicaceae Cardamine hirsuta, and three Leguminosae plants Medicago truncatula, Lotus japonicus, and pea (Pisum sativum) (Wang and Chen, 2013; Bar and Ori, 2015). Several excellent related reviews have previously been published, but these are either relatively old or focus primarily on the species tomato and C. hirsuta rather than M. truncatula and Leguminosae plants (Hofer and Ellis, 1998; Goliber et al., 1999; Kessler and Sinha, 2004; Blein et al., 2010; Efroni et al., 2010; Koenig and Sinha, 2010; Bar and Ori, 2014; Du et al., 2018; Wang H. et al., 2021). The leaves of Leguminosae plants, however, display a great diversity in compound leaf patterns, ranging from pinnate and palmate to higher-ordered complicated, and leaflets in these leaves usually show almost uniform morphology (He et al., 2020); moreover, some species from the Cercideae tribe (Caesalpinioideae) and the Desmodium genus (Papilionoideae) have a simple leaf morphology (Sprent, 2007, 2008). Over the last two decades or so, the molecular basis of this morphological diversity in Leguminosae plants has attracted a high level of interest (Hofer et al., 1997, 2009; Hofer and Ellis, 1998; Champagne et al., 2007; Wang et al., 2008, 2013; Hofer and Noel Ellis, 2014; Jeong et al., 2017; Moreau et al., 2018; Jiao K. et al., 2019). Recent studies in model legume $M$. truncatula identified several regulators involved in the compound leaf development, leading to a growing knowledge of the genetic control of the compound leaf patterning (Chen, 2018; Table 1; Figures 1A,B). M. truncatula is a close relative of alfalfa (Medicago sativa), the most cultivated forage plant that represents the most economically valuable forage for animal feed but has a limited genetic base for breeding programmers (Chen et al., 2020; Shen et al., 2020). This review aims to summarize the current knowledge about how the leaf morphogenesis of $M$. truncatula is regulated by the coordination of genetic factors, hormones, and other signals, and finally to pattern the compound leaf. It also includes some comparisons of the molecular mechanisms between leaf development of different model species and offers useful information for the molecular design of legume crops.

\section{PATTERN FORMATION AND MORPHOGENESIS IN COMPOUND LEAF DEVELOPMENT OF Medicago truncatula}

The ontogeny of leaf development can be conventionally divided into three continuous and overlapping phases: initiation, primary morphogenesis, and secondary morphogenesis (Efroni et al., 2010; Bar and Ori, 2015). Leaf primordia that lead to either simple or compound shapes are initiated from the flanks of the shoot apical meristem (SAM) and produced in series separated by a time period termed plastochron $(\mathrm{P})$. Universally, leaf primordia at sequential orders of plastochrons (P1, P2, P3, and P4...) are used to describe their developmental stages. The latest emerging leaf primordium is termed P1, the next oldest leaf primordium P2, and so forth, whereas the leaf founder cell population is designated as P0. Leaf initiation, that is stages P0 to $\mathrm{P} 1$, refers to the process of the recruitment of leaf founder cells (P0) on the peripheral zone of SAM and the subsequent formation of a protrusion (P1) after early cell division. After initiation, leaf primordia proceed with the second phase, the primary morphogenesis, which includes the establishment of three polarity axes (adaxial-abaxial, proximal-distal, and mediolateral), the specification of the primordial lamina, petiole, and other organs in leaves (i.e., leaflets in compound leaves) and the formation of marginal structures such as lobes and serrations (Du et al., 2018). The final phase is secondary morphogenesis, which involves limited cell division and extensive cell expansion and differentiation, leading to the attainment of final leaf shape and size (Gonzalez et al., 2012). Because of the main role of secondary morphogenesis in promoting laminar outgrowth and organ elongation rather than organ pattern of the leaf, it is generally believed that the controlling mechanisms of this process are likely to have greater similarities than differences between simple and compound leaf development. Overall, different from simple leaf development, compound leaf development contains a specific morphogenetic process during the primary morphogenesis, namely the formation of separated leaflet primordia, and this process largely determines the final leaflet number and arrangement (He et al., 2020). Therefore, in this review, the authors mainly dissect the regulators and pathways controlling the primary morphogenesis of the compound leaf in $M$. truncatula, with a particular concern about the mechanisms responsible for the pattern formation.

In $M$. truncatula, the first leaf following the appearance of the cotyledons is unifoliate in the juvenile form in contrast to subsequent trifoliate leaves in adult form, which consist of a pair of lateral leaflets and a terminal leaflet at the distal end of a petiole subtended by a pair of stipules (Wang et al., 2008; Figure 1A). Each leaflet in either unifoliate leaves or trifoliate leaves has an independent pulvinus at the base of the lamina, functioning as the motor organ for the nyctinastic leaf movement (Chen et al., 2012; Zhao et al., 2021). Our description and discussion are concentrated on the development of the trifoliate leaves where most studies have been focused on.

The trifoliate leaf is initiated as a strip of cells termed common primordia (P1) outgrowth along the SAM periphery, and later it progresses into primary morphogenesis, which includes most critical developmental events determining the leaf pattern (Wang et al., 2008; Chen, 2019; Figure 2). At the late P1 stage, stipule primordia become apparent at the proximal end of the common leaf primordium. During the P2 stage, a pair of lateral leaflet primordia were initiated between the stipule and the common primordium which later was differentiated into the terminal leaflet primordium; at the same time, boundaries were sequentially established between the stipule and lateral leaflet primordia, and between the lateral and terminal leaflet primordia (Figure 2A). Up to the late P3 stage, the three separated leaflet primordia were already formed, and the basic structure of the trifoliate leaf was established (Figure 2B). Then, during stages $\mathrm{P} 3$ to $\mathrm{P} 4$, another important and characteristic developmental event is that the abaxial surface of each leaflet 
TABLE 1 | Functionally characterized genes involved in compound leaf development.

\begin{tabular}{|c|c|c|c|}
\hline Genes & Annotation of the encoded proteins & Function in leaf development & References \\
\hline SINGLE LEAFLET1 (SGL1) & FLORICAULA (FLO)/LEAFY (LFY) ortholog & Lateral leaflet initiation; petiole length & Wang et al., 2008 \\
\hline PALMATE-LIKE PENTAFOLIATA1 (PALM1) & Cys(2)His(2) zinc finger transcription factor & Leaflet number and arrangement & $\begin{array}{l}\text { Chen et al., 2010; Peng } \\
\text { et al., } 2017\end{array}$ \\
\hline SMOOTH LEAF MARGIN1 (SLM1)/MtPIN10 & $\begin{array}{l}\text { An auxin efflux carrier protein homologous to } \\
\text { Arabidopsis PIN-FORMED1 (PIN1) }\end{array}$ & $\begin{array}{l}\text { Terminal leaflet number; lateral leaflet } \\
\text { number; marginal serrations }\end{array}$ & $\begin{array}{l}\text { Peng et al., 2011; Zhou } \\
\text { et al., } 2011\end{array}$ \\
\hline Fused Compound Leaf1 (FCL1) & $\begin{array}{l}\text { A class M KNOX protein homologous to } \\
\text { Arabidopsis KNATM }\end{array}$ & $\begin{array}{l}\text { Boundary formation between leaflets; } \\
\text { petiole and rachis length }\end{array}$ & Peng et al., 2011 \\
\hline STENOFOLIA (STF) & $\begin{array}{l}\text { WUSCHEL-like homeobox (WOX) } \\
\text { transcriptional regulator }\end{array}$ & $\begin{array}{l}\text { Blade expansion in the mediolateral } \\
\text { axis; leaf vascular patterning }\end{array}$ & $\begin{array}{l}\text { Tadege et al., 2011; Zhang } \\
\text { et al., } 2014\end{array}$ \\
\hline MtNAM/MtCUC2 & CUC/NAM transcription factor & Boundary formation between leaflets & Cheng et al., 2012 \\
\hline NODULE ROOT (NOOT)/MtBOP1 & $\begin{array}{l}\text { A BTB/POZ-ankyrin domain protein } \\
\text { orthologous to Arabidopsis BOPs }\end{array}$ & Stipule & Couzigou et al., 2012 \\
\hline $\begin{array}{l}\text { ELONGATED PETIOLULE1 } \\
(E L P 1) / P E T I O L U L E-L I K E ~ P U L V I N U S ~(P L P)\end{array}$ & $\begin{array}{l}\text { A LOB DOMAIN-CONTAINING PROTEIN (LBD) } \\
\text { transcription factor homologous to Arabidopsis } \\
\text { LOB }\end{array}$ & Pulvinus & $\begin{array}{l}\text { Chen et al., 2012; Zhou } \\
\text { et al., } 2012\end{array}$ \\
\hline MtAGO7/LOBED LEAFLET1 (LOL1) & $\begin{array}{l}\text { An ortholog of Arabidopsis ARGONAUTE7 } \\
\text { (AGO7) }\end{array}$ & Marginal serrations & $\begin{array}{l}\text { Zhou et al., 2013; Peng } \\
\text { et al., } 2017\end{array}$ \\
\hline MtPHAN & ARP MYB transcription factor & $\begin{array}{l}\text { Leaf adaxial-abaxial polarity; blade } \\
\text { planar shape; lateral leaflet placement; } \\
\text { stipule; marginal serrations }\end{array}$ & $\begin{array}{l}\text { Ge et al., 2014; Zhou et al., } \\
2014\end{array}$ \\
\hline BIG SEEDS1 (BS1) & $\begin{array}{l}\text { A TIFY transcription factor homologous to } \\
\text { Arabidopsis PEAPOD1 (PPD1) and PPD2 }\end{array}$ & Leaf organ size & Ge et al., 2016 \\
\hline$M t B R / 1$ & $\begin{array}{l}\text { A leucine rich repeat receptor protein kinase } \\
(L R R-R L K)\end{array}$ & $\begin{array}{l}\text { Leaf polarity; blade planar shape; leaf } \\
\text { organ size }\end{array}$ & $\begin{array}{l}\text { Cheng et al., 2017; Kong } \\
\text { et al., } 2021\end{array}$ \\
\hline HEADLESS (HDL)/MtWUS & WUSCHEL homolog & $\begin{array}{l}\text { Proximal-distal growth; marginal } \\
\text { serrations }\end{array}$ & $\begin{array}{l}\text { Meng et al., 2019; Wang } \\
\text { et al., } 2019\end{array}$ \\
\hline $\begin{array}{l}\text { AGAMOUS-LIKE FLOWER (AGLF)/AGAMOUS } \\
\text { AND TERMINAL FLOWER (AGTFL) }\end{array}$ & $\begin{array}{l}\text { A nucleus-localized protein containing a } \\
\text { putative Myb/SANT-like DNA-binding domain } \\
\text { and a PKc kinase domain }\end{array}$ & $\begin{array}{l}\text { Proximal-distal growth; petiole and } \\
\text { rachis length }\end{array}$ & $\begin{array}{l}\text { Zhang et al., 2019; Zhao } \\
\text { et al., 2019; Zhu et al., } \\
2019\end{array}$ \\
\hline PINNATE PENTAFOLIATA1 (PPF1)/MtREV1 & $\begin{array}{l}\text { Class III homeodomain-leucine zipper } \\
\text { (HD-ZIPIII) transcription factor }\end{array}$ & $\begin{array}{l}\text { Leaflet number and arrangement; } \\
\text { adaxial-abaxial polarity of terminal } \\
\text { leaflet }\end{array}$ & Zhou et al., 2019 \\
\hline $\begin{array}{l}\text { Lateral Leaflet Suppression } 1 \\
\text { (LLS1)/MtYUCCA1 }\end{array}$ & $\begin{array}{l}\text { A flavin monooxygenase homologous to } \\
\text { Arabidopsis YUCCA1 }\end{array}$ & Outgrowth of lateral leaflet; leaf venation & Zhao et al., 2020 \\
\hline PINNATE-LIKE PENTAFOLIATA1 (PINNA1) & $\begin{array}{l}\text { A BEL1-like homeodomain protein homologous } \\
\text { to Arabidopsis BLH11 }\end{array}$ & Leaflet number and arrangement & He et al., 2020 \\
\hline $\begin{array}{l}\text { Dwarf and Increased Branching } 1 \\
\text { (DIB1)/SMALL AND SERRATED LEAF } \\
\text { (SSL)/MtGA3OX1 }\end{array}$ & Arabidopsis GA3-oxidase 1 (GA3ox1) homolog & $\begin{array}{l}\text { Leaf organ size; petiole and rachis } \\
\text { length; marginal serrations }\end{array}$ & $\begin{array}{l}\text { Zhang et al., 2020; Wen } \\
\text { et al., } 2021\end{array}$ \\
\hline Mini Plant 1 (MNP1)/MtCPS & Copalyl diphosphate synthase & $\begin{array}{l}\text { Leaf organ size; petiole and rachis } \\
\text { length }\end{array}$ & Guo et al., 2020 \\
\hline $\begin{array}{l}\text { MINI ORGAN1 (MIO1)/SMALL LEAF AND } \\
\text { BUSHY1 (SLB1) }\end{array}$ & F-box protein & $\begin{array}{l}\text { Leaf organ size; proximal-distal growth; } \\
\text { pulvinus }\end{array}$ & $\begin{array}{l}\text { Yin et al., 2020; Zhou et al., } \\
2021\end{array}$ \\
\hline WRINKLED FLOWER AND LEAF (WFL) & 3-ketoacyl-CoA synthase & $\begin{array}{l}\text { Cuticular wax; leaflet separation; blade } \\
\text { planar shape }\end{array}$ & Yang et al., 2021 \\
\hline MtDWARF4A (MtDWF4A) & $\begin{array}{l}\text { A cytochrome P450 protein orthologous to } \\
\text { Arabidopsis DWARF4 }\end{array}$ & $\begin{array}{l}\text { Length of petiole, rachis, and pulvinus; } \\
\text { blade planar shape }\end{array}$ & $\begin{array}{l}\text { Kong et al., 2021; Zhao } \\
\text { et al., } 2021\end{array}$ \\
\hline MtLMI1a and MtLMI1b & $\begin{array}{l}\text { HD-Zip I transcription factors homologous to } \\
\text { Arabidopsis LMl1 }\end{array}$ & Marginal serrations & Kong et al., 2021 \\
\hline $\begin{array}{l}\text { MAIN STEM DWARF1 (MSD1)/MtGA200x1, } \\
\text { MtGA20ox7, and MtGA20ox8 }\end{array}$ & GA 20-oxidase & Leaf organ size & Li et al., 2021 \\
\hline
\end{tabular}

primordium outgrows the adaxial surface, resulting in the leaflet primordia becoming folded (Figure 2C). Beginning from the P4 stage, the specification of petiole, rachis, and pulvinus and the formation of marginal serrations occurred in succession (Figures 2D,E). Primary morphogenesis occurs during very young stages when the leaf is still protected by older leaves at the shoot apex, while secondary morphogenesis encompasses a much longer time period and represents an increase in surface area and volume of several thousandfold. Trichomes, as a maker of cell differentiation, firstly emerge in late P2 from the abaxial surface of the terminal leaflet primordium and later were gradually developed from the stipule, lateral leaflet, petiole, and 


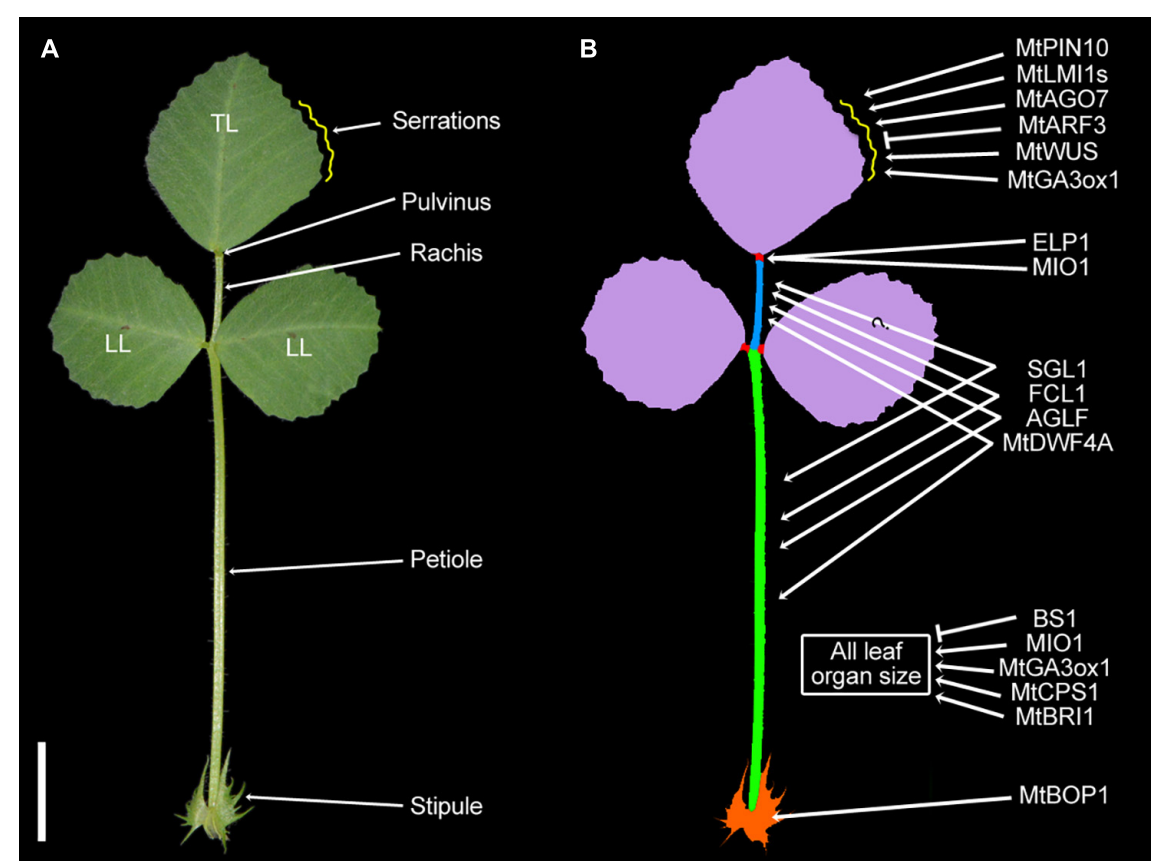

FIGURE 1 | Genes associated with the morphology of the Medicago truncatula trifoliate leaf. (A) The typical trifoliate leaf of $M$. truncatula consists of a terminal leaflet (TL), a pair of lateral leaflets (LL), a central rachis, and a petiole subtended by a pair of stipules (St). Each leaflet has a pulvinus at the base of the blade, functioning as the motor organ for leaf movement. The distal part of the blade ( $\sim 3 / 4$ midvein) forms serrations (yellow curve) along the edges. (Bar, $2 \mathrm{~cm}$.) (B) The diagram of the trifoliate leaf and some of the functionally characterized genes involved in regulating the morphology of serrations, pulvinus, rachis, petiole, and rachis of the trifoliate leaf

rachis primordia, and up to P5 stage, they densely covered the leaf surfaces, with especially abundance on the abaxial surface and the petiole and rachis (Figures 2A-D). During P5 and later stages, leaf cells mainly undergo cell-fate determination, differentiation, and expansion; the vasculature, leaf margins, and other specialized epidermal cells such as trichomes and stoma accomplish their differentiation to make a mature leaf. Usually, up to the P8 stage, the flattened shape of leaves was established.

\section{LEAF INITIATION}

The SAM is the source of all cells that ultimately form the aboveground architecture of plants, including the subset that ends up building the leaves (Vernoux et al., 2021). The homeobox gene WUSCHEL (WUS), which is specifically expressed in the organizing center of the SAM, plays a central role in the formation and maintenance of the shoot meristem activity (Schoof et al., 2000); loss-of-function mutations in WUS result in the misspecification of stem cells and the premature termination of meristem activity (Lenhard et al., 2001). In M. truncatula, in addition to a conserved role in the SAM and axillary meristem maintenance, the HEADLESS (HDL)/MtWUS has been implicated in the regulation of both the leaf proximal-distal axis elongation and the leaf margin morphology (Meng et al., 2019; Wang et al., 2019).

Leaf founder cells are part of the SAM and cannot be easily distinguished from other cells in histological appearance, but have certain cellular characteristics, including dense cytoplasm, very small vacuoles, and a high cell division rate (Verdeil et al., 2007; Yruela, 2015). The acquisition of founder cell identity is determined by specific gene expression and hormone signaling programs, and some molecular characteristics are: (i) the class I KNOTTED1-LIKE HOMEOBOX (KNOXI) genes that principally function to maintain the SAM identity are excluded from founder cells (Long et al., 1996; Hake et al., 2004); (ii) genes promoting organ specification and differentiation are activated, such as ASYMMETRIC LEAVES1/ROUGH SHEATH2/PHANTASTICA (collectively named $A R P$ ) and other adaxial-abaxial polarity genes (Fukushima and Hasebe, 2014); (iii) PIN-mediated the local auxin accumulation triggers the primordium bulging (Furutani et al., 2014). The initiation program would be highly conserved in $M$. truncatula which was evident from the following two considerations. At first, KNOXI genes are down-regulated at the site of the incipient leaf primordium where some adaxial-abaxial polarity genes such as $M$. truncatula ARGONAUTE7 (MtAGO7)/LOBED LEAFLET1 (LOL1), AUXIN RESPONSE FACTOR3 (MTARF3), PINNATE PENTAFOLIATA1 (PPF1)/MtREVOLUTA1 (MtREV1), and MtYABBY3 are activated (Zhou et al., 2013, 2014; Peng et al., 2017). Secondly, the initiation is proved to correspond to transient auxin maxima that probably generated by both Lateral Leaflet Suppression 1 (LLS1)/MtYUCCA1-mediated local biosynthesis (Zhao et al., 2020) and SMOOTH LEAF MARGIN1 (SLM1)/MtPIN10mediated polar transport (Peng and Chen, 2011; 

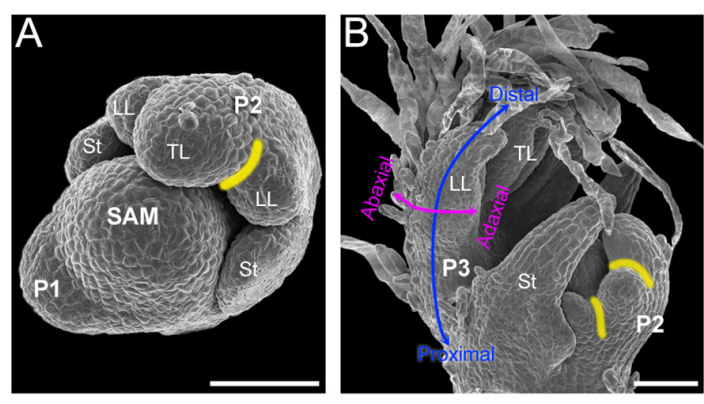

E

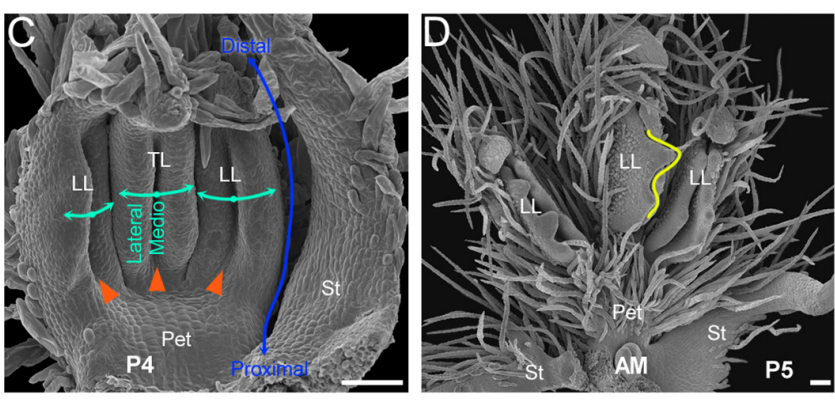

Secondary morphogenesis

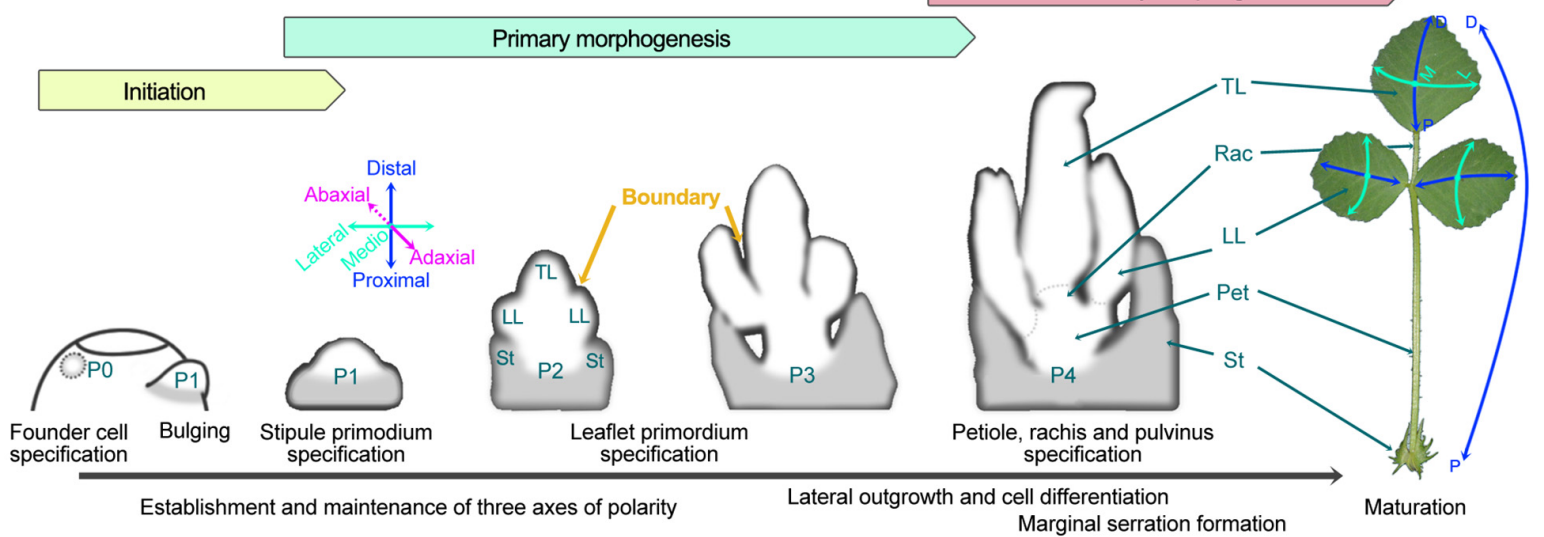

FIGURE 2 | The ontogeny of compound leaf development in M. truncatula. (A-D) SEM images of the shoot apical meristem (SAM) and/or developing leaf primordia. (A) The organization of the shoot apex with two leaf primordia developed at the SAM periphery. Primordia are named according to the plastochron (P) age: the latest emerging primordium is termed P1, the next oldest primordium P2, etc. The yellow curve marks the boundary between the terminal leaflet (TL) and the lateral leaflet (LL) primordia. St, stipule. (B) The organization of the shoot apex shows the SAM protected by P2 and P3 leaf primordia. Curved arrows mark the adaxial-abaxial (pink) and proximal-distal (blue) axes of leaf asymmetry. (C) Adaxial side view of the P4 leaf primordium. Cyan curved arrows mark the mediolateral axis. During stages P3 to P4, due to the abaxial surface outgrows the adaxial surface, the leaflet primordia became folded (orange triangle). (D) Adaxial side view of the P5 leaf primordium with the serrations (yellow curve) being formed. Pet, petiole. (Bars, $50 \mu \mathrm{m}$ ). (E) Diagrams of compound leaf primordia at successive stages of ontogeny. The leaf development of $M$. truncatula can be divided into three successive phases. The first is the initiation of leaf primordium from the peripheral zone of SAM. The following is primary morphogenesis, during which three axes of leaf polarity are established, and three separated leaflet primordia, as well as primordial petiole and rachis, are formed. The last is secondary morphogenesis, during which the vasculature, leaf margins, and other specialized epidermal cells such as trichomes and stoma accomplish their differentiation to make a mature leaf. A mature trifoliate leaf exhibits both global and local polarity along the proximal-distal axis (rightmost): the global proximal-distal polarity is manifest in the distribution of distinct specialized organs along the proximal-distal axis (blue and long double-headed arrow), while each leaflet exhibits independent local proximal-distal polarity (blue and short double-headed arrows). Rac, rachis.

Zhou et al., 2011). Their detailed descriptions have been discussed the below sections.

\section{LFY PLAYS A CENTRAL ROLE IN THE TRIFOLIATE PATTERN FORMATION}

How ordered leaflets are formed to a specific pattern is a fundamental question of compound leaf development. The pattern formation is largely dependent on maintaining and modulating a transient morphogenetic activity in the early leaf primordia which directs temporal and spatial patterns of the leaflet initiation (Bar and Ori, 2015). In most compoundleafed species including tomato and C. hirsuta, in addition to the role in promoting and maintaining SAM indeterminacy, KNOX I genes also play a key role in maintaining transient indeterminacy and morphogenetic activity in early compound leaf primordia (Hareven et al., 1996; Hay and Tsiantis, 2006;
Challa et al., 2021). As mentioned above, KNOX I genes are specifically expressed in SAM and are down regulated in the incipience of leaf primordium across angiosperms (Vollbrecht et al., 1991; Bharathan et al., 2002). The down-regulation of KNOX I genes expression is permanent during simple leaf development, but short-term expression activation occurs in the early stages of compound leaf development, resulting in the initiation of leaflet primordia from the margin of compound leaf primordia (Hake et al., 2004; Hay and Tsiantis, 2006). Overexpression of KNOX I genes led to extra leaflet production (Hareven et al., 1996; Hay and Tsiantis, 2006), while the lossof-function mutation in KNOX I genes resulted in simplelike leaves (Rast-Somssich et al., 2015). The reactivation of KNOX I genes in developing compound leaves is also seen in most legumes, but not detected in some legumes belonging to the inverted-repeat-lacking clade (IRLC), including pea and M. truncatula (Champagne et al., 2007). In IRLC legumes, the role of KNOX I genes is completely replaced by the FLORICAULA 
(FLO)/LEAFY (LFY) orthologs UNIFOLIATA (UNI) and SINGLE LEAFLET1 (SGL1) (Hofer et al., 1997; Wang et al., 2008; Zhou et al., 2014). LFY and its orthologs are highly conserved in plants and play a central role in specifying floral meristem identity in angiosperms (Sayou et al., 2014). In both pea and M. truncatula, loss-of-function mutation of SGL1 not only leads to defective in floral development, producing inflorescence-like structures but also converts compound leaves into simple-like leaves (Hofer et al., 1997; Wang et al., 2008). M. truncatula SGL1 has specifically expressed in central regions of the earliest leaf common primordia, later in terminal leaflet primordia, and last in the developing rachis (He et al., 2020; Zhao et al., 2020); this expression pattern is remarkably similar to that of ChSTM in the earliest stages of leaf development in C. hirsuta (Barkoulas et al., 2008). Interestingly, in some non-IRLC legumes, that is, soybean (Glycine max), L. japonicus, and mungbean (Vigna radiata), RNAi silencing or loss-of-function mutations of $L F Y$ orthologs also resulted in decreased leaflet number or even a simple leaf-like pattern, despite that KNOX I genes are detected in the leaf primordia (Champagne et al., 2007; Wang et al., 2013; Jiao K. et al., 2019), suggesting important roles for both KNOX I and LFY genes in leaf pattern formation in these species. It is not clear at present how KNOX I and LFY are coordinated to orchestrate the compound leaf development of the non-IRLC legumes.

During compound leaf pattern formation, how the KNOX I or LFY/SGL1-associated morphogenetic activity is directly regulated to ensure a correct leaf pattern is a central question. Recent publications suggest that the class II KNOX genes (KNOX II) (KNAT3, KNAT4, and KNAT5) confer opposing activities with KNOX I genes to suppress leaflet initiation in the simple leaf developmental program of Arabidopsis (Furumizu et al., 2015; Challa et al., 2021). Two important transcription factors were reported as repressors of the SGL1 expression during the pattern formation of the $M$. truncatula trifoliate leaves. PALMATE-LIKE PENTAFOLIATA1 (PALM1) encodes a Cys(2)His(2) zinc finger transcription factor that directly binds to the SGL1 promoter region and represses its transcription (Chen et al., 2010). PALM1 especially acts in the lateral leaflet primordia; in palm1 mutants, SGL1 expression was ectopically detected in the lateral leaflet region that caused two (rather than one) pairs of lateral leaflet formation, resulting in five leaflets organized into a palmatelike pattern. PINNA1-LIKE PENTAFOLIATA1 (PINNA1) gene encodes a BEL1-like homeodomain protein and its loss-offunction mutations led to a compound leaf pattern of five leaflets arranged pinnately (He et al., 2020; Wang and Jiao, 2020). PINNA1 proteins also directly bind to specific regions of the SGL1 promoter and inhibit the transcription. PINNA1 expression was found in both terminal and lateral leaflet primordia, and predominantly in the adaxial domain of the leaflet. In pinna1 mutants, an ectopic SGL1 expression was observed only in the early terminal leaflet primordia that thus initiated two additional leaflet primordia at the base, but not in the lateral leaflet primordia because of the existence of the functional PALM1 genes.

The combination of palm 1 and pinnal mutations results in higher-ordered compound leaves consisting of two orders and up to 13 leaflets (He et al., 2020). The five first-order leaflets in a palmate arrangement are formed in a process identical to that described for the five leaflets in palm1 leaves, while the second-order leaflets located on the petiolules of the first-order leaflets are formed in a manner similar to the additional pair of leaflets developing in pinna1 leaves. Elevated SGL1 expression was found to be associated with all leaflet production. The in vivo and in vitro biochemical analysis revealed that both PALM1 and PINNA1 proteins can bind to the SGL1 promoter to repress its expression, and they also can form a protein complex. In conclusion, during the pattern formation of trifoliate leaves, PINNA1 acts alone in the terminal leaflet region, while PALM1 functions as a "master regulator" role and PINNA1 as a "secondary regulator" role, to repress the SGL1 expression and the associated morphogenetic activity (Figure $\mathbf{3 A}$ ). In another word, either PINNA1 or PALM1 could repress the SGL1 in the terminal or lateral leaflets region respectively, but PINNA1 only repress SGL1 in the absence of PALM1.

\section{AUXIN IS IMPORTANT FOR LEAFLET INITIATION AND THE SUBSEQUENT OUTGROWTH}

The compound leaf development in different species is tightly associated with several hormones signaling pathways. Among them, auxin received particular attention that numerous auxin biosynthetic enzymes, transporters, and signaling components have been reported to be involved in multiple processes of leaf development, including leaf and leaflet initiation, leaflet separation, and patterning, and blade outgrowth (Xiong and Jiao, 2019). Auxin is essential for the initiation of leaf common primordia from the flanks of SAM and leaflet primordia from the margins of leaf common primordia. Accumulation of auxin in initiating organs is driven by the activity of the PIN family of auxin efflux carriers (Wisniewska et al., 2006). In C. hirsuta, loss-of-function of PINFOR MED1 (ChPIN1) resulted in a decreased leaf production and a simple-like leaf pattern (Barkoulas et al., 2008). The ChPIN1 protein establishes local auxin activity maxima at leaf margin in the same manner as that it functions in SAM periphery, and thus facilitates the formation of lateral leaflets. In $M$. truncatula, SMOOTH LEAF MARGIN1 (SLM1)/MtPIN10 is a functional auxin efflux transporter orthologous to PIN1 (Peng and Chen, 2011; Zhou et al., 2011). The compound leaf development in slm1/mtpin10 mutants exhibited severe defects, including the decrease in marginal serrations, increase in terminal leaflet number, and a simultaneous reduction in lateral leaflet number, accompanied by reduced expression of SGL1 (Zhou et al., 2011). MtPIN10 is apically localized at the epidermal cells of the leaf primordia and marks the site of incipient primordia, and it also directs auxin maxima at the tips of serrations. It is interesting that the defects in the compound leaf pattern of $\operatorname{sim} 1 / m$ mpin10 (not much change in leaflet number) are significantly different from that of chpin1 (almost no leaflet), indicating the auxin regulators acting in diverse manners in different developmental contexts. 
Auxin biosynthetic enzymes like YUCCAs are also reported to be necessary for the initiation of leaf and leaflet primordia and the blade outgrowth. A conserved function of YUCCAs on leaf vascular development was found in several species. The lossof-function of multiple YUCCA genes in Arabidopsis resulted in plants with auxin-deficient phenotypes of short and narrow leaf blades and reduced leaf veins (Zhao et al., 2001; Cheng et al., 2007). The yucca1 mutant of pea (crispoid/psyuc1) has altered vein density and placement, with missing or underdeveloped tendrils and leaflets at low frequency (McAdam et al., 2017). In M. truncatula, the Lateral Leaflet Suppression1 (LLS1) gene encodes a key auxin biosynthetic enzyme MtYUCCA1, which plays a very important role in the compound leaf pattern formation (Zhao et al., 2020). The $l l s 1$ mutants are sever defective in vascular tissue development of blade, and the outgrowth of lateral leaflets was significantly suppressed with a morphology ranging from severely malformed or underdeveloped to small blade size. MtYUCCA1 is expressed in the emerging primordia as early as P0 and P1 stages, then at the basal regions between the terminal leaflet and lateral leaflet primordia of P2 and P3 stages, and the vascular tissues of leaflet primordia at later stages. As YUCCA proteins convert indole-3-pyruvic acid IPA to natural auxin IAA (Cao et al., 2019), the development of leaflets in trifoliate leaves therefore should be dependent on MtYUCCA1-catalyzed auxin generation and MtPIN10-driven auxin redistribution (Figure 3B).

How auxin signals are translated into programs of compound leaf morphogenesis remains to be investigated. In the moststudied auxin-signaling pathway, class A AUXIN RESPONSE TRANSCRIPTION FACTORS (ARFs) bind to target genes to activate downstream gene expression, whereas Aux/IAA proteins inhibit the auxin response by interacting with ARF activators to inhibit gene expression (Xiong and Jiao, 2019; Israeli et al., 2020). In tomato, multiple ARFs were found to stabilize the developmental output of auxin during leaf patterning, wherein the class A ARFs, SIMP, SlARF19A, and SIARF19B function to promote leaflet initiation and outgrowth but are repressed in the intercalary regions between leaflets by the Aux/IAA protein ENTIRE (E) (Israeli et al., 2019). In M. truncatula, overexpression of the MtARF3 leads to a curling leaf margin with deep serrations or even palmate-like pentafoliate leaves with radialized blades in some cases, and MtARF3 proteins can directly interact with the PALM1 promoter to negatively regulate PALM1 expression (Zhou et al., 2013; Peng et al., 2017; Figure 3D). The role of MtARF3 in specifying abaxial cell fate is further discussed in the below section "Roles of the leaf polarity genes in the leaf pattern formation" but understanding the detailed molecular mechanism of MtARF3 in the auxin signaling pathway requires further research.

\section{BOUNDARY DEVELOPMENT DURING COMPOUND LEAF PATTERN FORMATION}

Compound leaf development is characterized by the formation of separated leaflet primordia during the early stages of ontogeny.
Leaflet primordia are initiated from marginal regions of the leaf common primordium and accompanying this process another key developmental event is the establishment of boundaries between leaflet primordia (Figures $2 \mathrm{~A}, \mathrm{E}$ ). The boundary that separates two cell groups of organs has a specific feature of restricted cell growth relative to surrounding tissues, which relies on its unique gene expression profiles and hormone signaling programs (Zadnikova and Simon, 2014; Hepworth and Pautot, 2015). The best-characterized boundary is the domain separating the lateral organs from the SAM, where auxin and brassinosteroids (BRs) are down-regulated. The LATERAL ORGAN BOUNDARY DOMAIN (LBD) family gene LATERAL ORGAN BOUNDARIES (LOB) is expressed in the SAM-toorgan boundary and functions to maintain a low level of BRs, which subsequently restricts cell growth and division. CUPshaped COTYLEDON (CUC)/NO APICAL MERISTEM (NAM) is a class of plant-specific NAC transcription factors that plays a central role in maintaining growth repression in boundaries (Aida et al., 1997; Blein et al., 2008). In addition to controlling SAM and organ separation, CUC/NAMs are also required for the boundary formation between leaflet primordia during compound leaf development (Blein et al., 2008). The silencing or mutation of CUC/NAM in different species all resulted in different degrees of fusion and decrease in the number of leaflets, whereas ectopic expression of CUC/NAM genes resulted in a compound leaf phenotype of increased leaflet number (Blein et al., 2008; Berger et al., 2009; Wang et al., 2013; Rast-Somssich et al., 2015; Jiao K. Y. et al., 2019). In M. truncatula, the CUC/NAM homologous gene $M t N A M$ is also specifically expressed in the boundary region of leaflets (Figure 3C), and mutations lead to leaflet fusion (Cheng et al., 2012). Leaves of the sgll mtnam double mutant greatly resembled the phenotype of the $s g l 1$ single mutant with a single leaflet pattern, while MtNAM expression is reduced in the sgl1 mutant but SGL1 expression was not altered in the mtnam mutant (Cheng et al., 2012), indicating that SGL1 is likely epistatic to MtNAM during the trifoliate leaf development and that the leaflet initiation is a prerequisite for leaflet delimitation.

Recently, the class M KNOX proteins, which lack the homeodomain, have been identified in Arabidopsis thaliana and tomato (Kimura et al., 2008; Magnani and Hake, 2008). Ectopic expression of the class M KNOX gene KNATM in A. thaliana leads to elongated petiole and narrow blade (Magnani and Hake, 2008). In tomatoes, the gain-of-function of the class M KNOX protein PETROSELINUM (PTS) increased the compound leaf complexity (Kimura et al., 2008). The M. truncatula Fused Compound Leaf1 (FCL1) gene is the orthologous gene of KNATM/PTS (Peng et al., 2011). Compound leaves in $f_{c l}$ mutants are simplified with fused or clustered leaflets and shortened petioles, but without rachises. Similar to that of sgl1 mutants, the reduction in the petiole length in the $f c l 1$ mutants is likely caused by reduced cell division but not cell expansion. During the earliest developmental stages, the FCL1 expression corresponds to the sites of leaf initiation (P0 to P1); at subsequent developmental stages, FCL1 was expressed at the proximal domain of developing leaf primordia (Figure 3C); in older developing leaves, FCL1 was expressed at petiole, rachis and the base of folded blades. This expression pattern of FCL1 
A
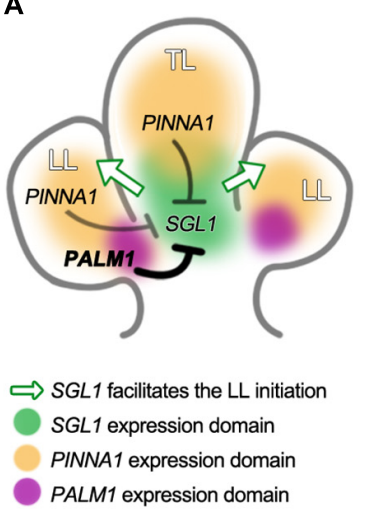

B

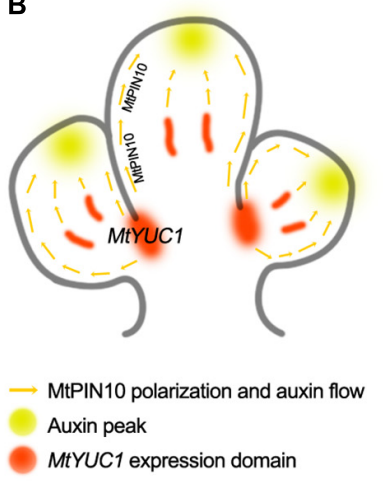

C

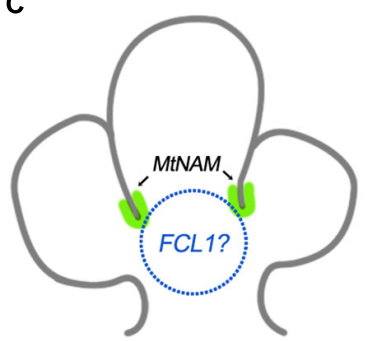

MtNAM expression domain

Presumed FCL1 expression domain
D
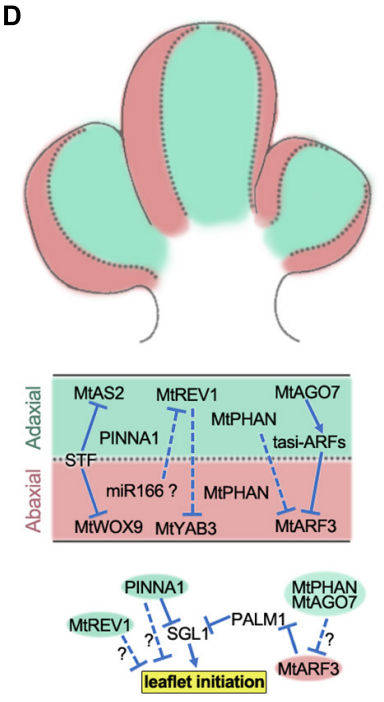

FIGURE 3 | Genes-network controlling the trifoliate pattern formation of M. truncatula. (A) Model for LFY/SGL1 pathway in trifoliate pattern formation with the diagram representing the P3 leaf primordium of three leaflet primordia but without stipule primordia. SGL1 is the key indeterminacy factor that maintains a transient morphogenetic activity and promotes the initiation of LL primordia (green arrows), while both PINNA1 and PALM1 negatively regulate the morphogenetic activity by directly inhibiting the expression of SGL1. PINNA1 acts alone in the TL primordia and plays a secondary role in the LL primordia (gray lines), where PALM1 functions as a master role (bold line). (B) Model for auxin actions during the trifoliate pattern formation. MtPIN10 polarization mediates auxin transport leads to the formation of auxin peaks to induce both TL and LL primordia bulging, and the MtYUC1 encoding auxin biosynthetic enzyme plays an essential role in LL growth. (C) Regulation of boundary development. MtNAM facilitates the separation of TL and LL primordia by inhibiting cell proliferation in the boundary region, FCL1 also plays a key role in the development of boundaries between TL and LL primordia. (D) Schematic view of the adaxial-abaxial patterns in leaflet primordia of the P3 leaf (upper panel), regulatory networks for the establishment and maintenance of adaxial-abaxial polarity (middle panel), and links between adaxial-abaxial polarity genes and the leaflet initiation (lower panel). MtAS2, MtAGO7, MtREV1, and PINNA1 are expressed in the adaxial domain of leaf primordia, MtWOX9, MtARF3, and MtYAB3 are expressed in the abaxial domain, and MtPHAN is expressed in both of the adaxial and abaxial domain, while STF is expressed at the adaxial-abaxial junction (middle domain). STF directly represses the expression of MtAS2 and MtWOX9, while MtPHAN and MtAGO7 negatively regulate transcription of MtARF3, MtREV1 represses the expression of MtYAB3. The adaxial-abaxial polarity genes MtPHAN, MtAGO7, and MtARF3 regulate the leaflet initiation through the LFY/SGL1 pathway. The adaxial polarity gene MtREV1 regulates the leaflet initiation through unknown mechanisms. The PINNA1 is mainly expressed in the adaxial domain and it negatively regulates the leaflet initiation through both the LFY/SGL1 pathway and an unknown mechanism independent of the SGL1 gene.

was greatly consistent with its roles in boundary separation and proximal-distal axis development, but the underlying mechanism remains undetermined.

The M. truncatula WRINKLED FLOWER AND LEAF (WFL) encodes a 3-ketoacyl-CoA synthase involved in the biosynthesis of very-long-chain fatty acids and cuticular wax. The $w f l$ mutants have dramatic developmental defects in leaves and floral organs, exhibiting wrinkled leaves throughout the growth period and fused floral organs during the reproductive period (Yang et al., 2021). WFL was expressed in epidermal cells of the SAM, leaf primordia, and floral organs. This study is in accordance with the previous report that the functional cuticle is important for maintaining lateral organ separation (Liu et al., 2021).

\section{ROLES OF THE LEAF POLARITY GENES IN THE LEAF PATTERN FORMATION}

Once leaf founder cells are specified at the SAM flank, the leaf polarity simultaneously begins to be established through highly organized cell division and differentiation along three axes: adaxial-abaxial (broadly equivalent to the dorso-ventral), mediolateral, and proximal-distal (Efroni et al., 2010). The side of the leaf primordium facing the SAM is called the adaxial/dorsal face, mainly responsible for capturing sunlight and photosynthesis, and the other side called the abaxial/ventral face is mainly responsible for gas exchange. The region connecting the adaxial and abaxial surfaces is defined as the middle domain. The mediolateral polarity represents the horizontal expansion of the blade. The proximal-distal polarity determines the growth direction of the leaf primordia and the relative placement of the blade and petiole. The proximal portion is close to SAM, which differentiates into petiole, while the region farthest from the SAM is the distal portion where the blade forms. Although the pattern of the leaf polarity is establishment along three axes, the adaxialabaxial axes play a decisive role. Only when the adaxial-abaxial polarity is established, the leaf can be extended, and the pattern of proximal-distal and the mediolateral can be further established (Efroni et al., 2010; Manuela and Xu, 2020).

\section{Adaxial-Abaxial Polarity Genes}

The MYB domain protein encoded by the ASYMMETRIC LEAVES1/ROUGH SHEATH2/PHANTASTICA (ARP) gene plays an important role in leaf initiation and the establishment of leaf adaxial-abaxial polarity (Waites et al., 1998; Timmermans et al., 1999; Byrne et al., 2000; Harrison et al., 2005). Mutations in 
PHANTASTICA of Antirrhinum abolished adaxial cell types and inhibited laminar growth (Waites et al., 1998). In A. thaliana and C. hirsuta, KNOX I and ARP genes are expressed in mutually exclusive domains, and the maintenance of the repressed state of $K N O X I$ genes in the leaf primordium depends on ARP genes (Byrne et al., 2000; Hay and Tsiantis, 2006). The antagonism between $A R P$ and KNOX $I$ is also important for the compound leaf development of C. hirsuta (Hay and Tsiantis, 2006; RastSomssich et al., 2015). C. hirsuta chas1 mutants have an altered expression pattern of KNOX I genes in leaf primordia, leading to an increased leaflet production. In tomatoes, down-regulation of $A R P$ results in a switch from pinnate into peltately palmate compound leaves with abaxialized petioles and reduced leaflet number (Kim et al., 2003). Loss-of-function of the pea ARP ortholog CRISPA causes various leaf abnormalities, including crisp leaf organs, narrowing leaflets, the curvature of petiole and rachis, and ectopic stipules on its petiole-rachis axis which is also associated with ectopic KNOX I genes expression (Tattersall et al., 2005). The M. truncatula mtphan mutants also exhibited severe compound leaf defects, including curling and deep serration of leaf margins, shortened petioles, increased rachises, petioles acquiring motor organ characteristics, and ectopic development of petiolules (Ge et al., 2014; Zhou et al., 2014). MtPHAN expresses throughout the SAM as well as in adaxial and abaxial sides of developing leaf primordia; KNOX I genes appear to uncouple from the PHAN regulation. Taken together, the effect of ARPs on leaf development and on KNOX I expression varies in different species, but it seems that, in compound leaf development, ARPs have much more important and complex roles on the petiole-rachis identity regulation than what is previously recognized.

The identity of adaxial surface cells depends on the activity of class III homeodomain-leucine zipper (HD-ZIP III) transcription factors, including PHABULOSA (PHB), PHAVOLUTA (PHV), and REVOLUTA (REV) (McConnell et al., 2001; Ochando et al., 2008). Single loss-of-function of $P H B, P H V$, or $R E V$ has no significant effect on the polarity development of lateral organs; simultaneous loss-of-function of $P H B P H V$ and $R E V$ abaxializes cotyledons, abolishes primary apical meristem, and in severe cases, eliminates the bilateral symmetry of lateral organs (Emery et al., 2003). It is well recognized that the adaxial expression of $P H B P H V$ and $R E V$ is restricted by microRNA165/166 ( $m i R 165 / 166)$, which are expressed in the abaxial domain and mediate the cleavage and degradation of HD-ZIP III mRNAs (Rhoades et al., 2002; Tang et al., 2003). Mutations in the homologous gene of $P H B$ results in curly leaf in cucumber (Cucumis sativus) (Rong et al., 2019); in rice, LATERAL FLORET 1 (LF1) is homologous to Arabidopsis $R E V$ and the gain-of-function mutant $l f 1$, in which $L F 1$ was expressed ectopically because miRNA165/166 could not act on the mutated LF1 mRNA, showed a phenotype of highly abaxialized and rolled leaves (Zhang et al., 2017; Zhang et al., 2021). There is only one $P H B / P H V$ gene but two REVOLUTA genes in M. truncatula (Zhou et al., 2019). Most leaves in the mtrev1 mutant consist of five leaflets arranged pinnately, with some cases of a trumpet-shaped terminal leaflet, of which the adaxial side is surrounded by the abaxial side. MtREV1 was preferentially expressed in the adaxial domain of leaf primordia at different developmental stages, and this polarized expression pattern would also depend on post-transcriptional regulation by miR165/166. Overexpression of MtmiR166-insensitive MtREV1 showed ectopic blade tissues forming along the midvein and on the abaxial side of the leaf (Zhou et al., 2019). These suggest that MtREV1 plays an important role both in maintaining the adaxial polarity of leaves and in the trifoliate pattern formation, and it will be interesting to further investigate how MtREV1 regulates compound leaf pattern formation and the nature of the relationship between adaxial-abaxial polarity and compound leaf patterning. The YABBY (YAB) family of transcription factors confers abaxial identity in A. thaliana (Siegfried et al., 1999), and $M t Y A B 3$ is similarly specific to the abaxial side in M. truncatula, while in mtrev1 mutants, the expression of $M t Y A B 3$ was observed in both adaxial and abaxial sides of leaf primordia (Zhou et al., 2019). However, the remaining yab mutants of $M$. truncatula were not characterized and the role of $M t Y A B$ genes needs to be further investigated.

In addition to $Y A B$ genes, the above-mentioned ARFs are another type of determinant of abaxial cell fate (Pekker et al., 2005). ARFs are regulated by a group of ta-siRNA named ta-siARFs, which are originated from the cleavage of TAS3 transcripts by ARGONAUTE7 (AGO7) coupled with miR390 (Adenot et al., 2006; Garcia et al., 2006; Hunter et al., 2006). It has been reported that the $M$. truncatula MtAGO7 is required for the biogenesis of ta-siARFs to negatively regulate the expression of MtARF3 (Zhou et al., 2013). MtAGO7 is predominantly expressed on the adaxial sides of both the leaf and leaflet primordia and its loss-of-function mutation results in lobed leaf margins and more widely spaced lateral organs. In wild-type, the ta-siARFs assumed to be expressed in the adaxial domain, and expression of MtARF3 is detected in the abaxial domain; but in mtago 7 mutants, putative ta-siARFs are dramatically reduced and the MtARF3 was highly expressed and extended into the adaxial domain (Zhou et al., 2013). Plants overexpressed the original MtARF3 exhibited downward-curled leaves and showed more serrations along the leaf margin, whereas overexpression of a mutated ARF3 carrying two altered ta-siARF target sites was phenotyped with obvious lobed leaf margin, mimicking the ago7-1 phenotype (Zhou et al., 2013).

As mentioned above, a recent study suggested that MtARF3 can directly interact with specific auxin response elements (AuxREs) in the PALM1 promoter and functions as a repressor to negatively regulate PALM1 transcription, while $M t A R F 3$ overexpression results in palmate-like pentafoliate leaves with radialized blades, which, to some degree, resembled the phenotype of the palm1 mutant (Peng et al., 2017). The MtARF3-PALM1 module may benefit from the involvement of MtPHAN and MtAGO7 in the adaxial domain. In either mtphan or mtago7 single mutants, MtARF3 expression was similarly elevated and detected in both the adaxial and abaxial domains; more surprisingly, in the mtphan mtago7 double mutants, $M t A R F 3$ transcripts increased drastically and even appeared much higher in the adaxial domain than the abaxial domain, accompanying the downregulated PALM1 expression and the change of compound leaf pattern from trifoliate to palmate-like 
pentafoliate with radialized blades. These interactions among MtPHAN, MtARF3, and PALM1 suggest a complex relationship among adaxial-abaxial polarity development, auxin signaling program, and compound leaf patterning.

\section{Mediolateral Polarity Genes}

Formation of the leaf blade requires growth along the mediolateral axis, and WOX1 genes were found to be specifically involved in this process in diverse eudicot species (Vandenbussche et al., 2009; Nakata et al., 2012; Zhuang et al., 2012; Vandenbussche, 2021; Wang C. et al., 2021). In A. thaliana, two WOX family genes, WUS-related HOMEOBOX1 (WOX1) and PRESSED FLOWER (PRS)/WOX3, are expressed at the middle domain between the adaxial and the abaxial domains at the P2 stage and the leaf margin at later stages. The WOX1 and PRS/WOX3 can inhibit the expression of adaxial-abaxial characteristic genes in the middle domain, whereas their own gene expression is repressed by KANADI (KAN) feedback in the abaxial domain (Nakata et al., 2012). In compound leaf development of $M$. truncatula, the WOX1 ortholog STENOFOLIA (STF) has conserved roles in promoting lamina outgrowth along the mediolateral axis (Tadege et al., 2011). The stf mutants showed a very narrow blade or bladeless phenotype with severe disruption of vein patterning. Similar to the expression patterns of WOX 1 and PRS/WOX 3 in Arabidopsis, $S T F$ is specifically expressed at the adaxial-abaxial junction of the early leaf primordia, and at the margin of the distal half portion of the leaflets in young developing leaves. The STF protein recruits the TOPLESS (MtTPL) protein to directly repress the LBD family gene $M t A S 2$ expression and promote cell proliferation at the adaxial-abaxial boundary (Zhang et al., 2014). A recent study found that MtWOX9 is an abaxial factor required for proper blade outgrowth in Medicago, and STF represses $M t W O X 9$ expression by directly binding to its promoter at multiple sites (Wolabu et al., 2021). It is, therefore, likely that STF establishes and maintains a cell proliferation zone at the adaxial-abaxial junction in the middle mesophyll and leaf margin by keeping adaxial and abaxial polarity factors away from this region (Figure 3D).

\section{Proximal-Distal Polarity Genes}

Medicago truncatula trifoliate leaves exemplify global and local polarity along the proximal-distal axis (Figure 2E). The global proximal-distal polarity is manifest in the distribution of distinct specialized organs along the proximal-distal axis: the proximal portion being of a petiole with a pair of stipules located at the proximal end, and the distal portion of three ovate leaflets connected to a central rachis through their pulvini at the lamina base. Each leaflet exhibits independent local proximal-distal polarity which is exemplified by the distal half portion of the lamina forming the acute apex and the proximal half forming the cuneate or slightly convex base, and by the marginal serrations forming in the distal portion $(\sim 75 \%)$ but absent in the proximal portion ( $\sim 25 \%)$.

In A. thaliana, two BTB/POZ domain-ankyrin repeat proteins BLADE-ON-PETIOLE1 (BOP1) and BOP2 are reported to regulate proximo-distal patterning and the bop1 bop2 double mutant develops blade-on-petiole structures (Ha et al., 2007). In pea, coch mutants carry mutations in the BOP1 homolog and have stipule phenotypes that vary from weak modifications (asymmetric shape) to spoon-like leaf structures and even complete conversion into complex pea leaf structures (Couzigou et al., 2012). COCH gene was expressed at the base of the developing leaf where stipules are formed. The Medicago BOP1 homolog, NOOT/MtBOP1, loss-of-function phenotype were simplified stipules with a reduced number of serrations (Couzigou et al., 2012). Recently, the Pea Stipules reduced $(\mathrm{St})$ gene was identified and it encodes a $\mathrm{C} 2 \mathrm{H} 2$ zinc finger transcription factor that is regulated by $\mathrm{COCH}$ (Moreau et al., 2018). St regulates both cell division and cell expansion in the stipule, and it has one highly homologous gene in Medicago, which awaits to be characterized in the future.

Both SGL1 and FCL1 are required for the development of petiole and rachis (Wang et al., 2008; Peng et al., 2011). The petiole was significantly shortened in the sgl1 leaves and the rachis was absent. In $f c l 1$ mutants, the petiole was also shorter than the wild-type counterparts and the rachis appears to be shortened or completely absent in different alleles. The average length of petiole epidermal cells was indistinguishable between fcll mutants and wild-type plants, indicating the reduced petiole elongation may be due to altered cell division activity in $f c l 1$ mutants. Mature leaves of sgl1 fcll double mutants were simple, resembling those of sgll mutants, and besides completely lacked petioles (Peng et al., 2011).

A novel nucleus-localized protein containing a putative Myb/SANT-like DNA-binding domain and a PKc kinase domain, AGAMOUS-LIKE FLOWER (AGLF)/AGAMOUS AND TERMINAL FLOWER (AGTFL), was recently reported to regulate the flower development of $M$. truncatula (Zhao et al., 2019; Zhang et al., 2019; Zhu et al., 2019). Loss-of-function of AGLF results in flowers with stamens and carpel transformed into extra whorls of petals and sepals. The mutants also displayed defects in compound leaf development; both the rachis and petiole were shortened while leaflets clustered together. In aglf mutants, leaflet elongation in the longitudinal direction is significantly affected, leading to a heart-shaped lamina with a retuse apex in contrast to the ovate lamina with an acute apex in wild-type plants. The MtWUS and MINI ORGAN1 (MIO1)/SMALL LEAF AND BUSHY1 (SLB1) are two important regulators for leaflet elongation along the proximal-distal axis. As mentioned above, the MtWUS has conserved functions in the SAM and AM maintenance; besides, mtwus mutants produced heart-shaped leaves that showed retuse apex and increased width/length ratio (Meng et al., 2019; Wang et al., 2019). In young leaves, the MtWUS was slightly expressed in the leaf lamina as a whole, but it was considered at the tips of the marginal serrations. The MIO1/SLB1 encodes an F-box protein, an ortholog of $A$. thaliana STERILE APETALA (SAP) (Yin et al., 2020; Zhou et al., 2021). The loss-of-function of MIO1/SLB1 severely reduced organ size. Leaves of mio1 mutants exhibited not only reduced size but also heart-shaped blade morphology. These studies indicate that the lamina growth along the proximal-distal axis of each leaflet is subject to a complex regulation, in which AGLF, MtWUS, and MIO1 would play 
important roles. However, the detailed mechanism of their action in this developmental process remains to be clarified.

\section{THE GENETIC CONTROL OF LEAF ORGAN SIZE AND MARGINAL SERRATIONS}

The overall leaf size is often characterized by its length and width, which are dependent on the growth along the proximal-distal and the mediolateral axes respectively. Cell proliferation and cell expansion are important basic processes promoting growth along the two axes. In Medicago, several molecules and signaling pathways responsible for these processes have been recently identified, including phytohormones, transcription factors, and other molecular regulators.

Gibberellin (GA) is involved in various processes of plant growth and development, including leaf expansion, seed germination, induction of flowering, and stem elongation. In M. truncatula, Dwarf and Increased Branching 1 (DIB1)/SMALL AND SERRATED LEAF (SSL) encodes a gibberellin $3 \beta$ hydroxylase (GA3ox) enzyme, catalyzing the final step of the biosynthetic pathway for bioactive GAs (Zhang et al., 2020; Wen et al., 2021). The mutant exhibits extreme dwarfism and an increased number of lateral branches, and besides, leaves of the mutant were extremely reduced in all organ sizes and bore a more pronounced leaf margin. Another component of GA biosynthesis in M. truncatula, Mini Plant 1 (MNP1), encodes a putative copalyl diphosphate synthase (CPS) implicating in the first biosynthetic step (Guo et al., 2020). The mutant also exhibits extreme dwarfism and very small leaves. MtGA3ox and MtCPS were shown to affect both cell proliferation and elongation because the shortened stem length of two mutant lines is due to a decrease in cell number and size. Three GA 20-oxidases catalyzing the late step of GA biosynthesis, MAIN STEM DWARF1 (MSD1) and its homologs MtGA20ox7 and MtGA20ox8, were recently identified in $M$. truncatula, and they play partially redundant roles in controlling the shoot elongation and the lateral organ size ( $\mathrm{Li}$ et al., 2021). The msd1 mutant exhibits a phenotype of the semidwarfed main stem but normal leaves, while the msd1 mtga20ox7 mtga20ox 8 triple mutant exhibits a severely dwarf phenotype with markedly reduced leaf size, mimicking the phenotypes of the dib1 and mnp1 mutants.

A well-characterized role for brassinosteroids (BRs) is their involvement in cell expansion and organ elongation (Bajguz et al., 2020). BR-deficient or -insensitive mutants of Arabidopsis exhibit phenotypes of dwarf, round leaves, shorter petioles, and infertility. Brassinosteroids Insensitive 1 (BRI1) is required for BR perception and initiation of subsequent signal transduction in Arabidopsis (Li and Chory, 1997). In Medicago, the loss-offunction mutant of MtBRI1 has typical BR-deficient phenotypes of extreme dwarfness and infertility, and its leaves were thickened, curled, dark green, and greatly reduced in size with the petioles and rachises failed to elongate (Cheng et al., 2017; Kong et al., 2021). MtDWARF4A (MtDWF4A), a gene encoding a cytochrome $\mathrm{P} 450$ protein orthologous to $A$. thaliana DWARF4, is required for the BR biosynthesis. The $m t d w f 4 a$ mutant exhibits mild BR-deficient phenotypes, semi-dwarfism, short petioles, and rachis, but normal fertility (Kong et al., 2021; Zhao et al., 2021). The MtDWF4A has a highly homologous copy designated as $M t D W F 4 B$, it will be critical to explore the possibilities of functional redundancy and diversification between $M t D W F 4 A$ and $M t D W F 4 B$ in the BR biosynthetic pathways (Zhao et al., 2021).

Medicago truncatula BIG SEEDS1 (BS1) encodes a member of group II of the TIFY transcription factor family and it plays a critical role in determining seed and leaf size (Ge et al., 2016). $B S 1$ is homologous to A. thaliana PEAPOD1 (PPD1) and PPD2. Loss-of-function of $B S 1$ leads to enlarged seeds, fruits, and leaves. As mentioned above, the F-box protein MIO1/SLB1 plays a positive role in organ size determination. Plants overexpressing MIO1/SLB1 had enlarged organs, and this is because MIO1/SLB1 forms part of SKP1/Cullin/F-box (SCF) E3 ubiquitin ligase complex, targeting BS1 proteins for degradation (Yin et al., 2020; Zhou et al., 2021). The pathway of BS1 and MIO1/SLB1 may mainly modulate primary cell proliferation during the early stages of leaf development to control the leaf size.

In A. thaliana, CUC2 promotes the establishment of PIN1 convergence points to generate auxin maxima at the tip of serrations (Bilsborough et al., 2011). M. truncatula leaflets have serrations on the distal part $(\sim 3 / 4$ midvein $)$ of the lamina margin, and the involved regulators have been recently reviewed (Wang H. et al., 2021). MtPIN10 plays a key role in generating the auxin maxima at the tips of serrations, while MtNAM is also involved in the marginal serration formation (Zhou et al., 2011). MtLMI1s encoding HD-Zip I transcription factors homologous to $A$. thaliana LATE MERISTEM IDENTITY1 (LMI1) and C. hirsuta REDUCED COMPLEXITY (RCO) (Vlad et al., 2014; Kierzkowski et al., 2019), directly activate the expression of SLM1 to regulate the auxin distribution along leaf margin (Wang X. et al., 2021). The elaboration of leaf margin formation also requires the determination of the degree of marginal indentation, which is regulated by the MtAGO7mediated TAS3 ta-siRNA pathway through the suppression of MtARF3 expression (Zhou et al., 2013).

\section{THE PULVINUS DEVELOPMENT IN Medicago truncatula}

The pulvinus-driven nyctinastic leaf movement is a common and characteristic phenomenon found in legume plants. Many legume plants have compound leaves consisting of multiple leaflets. Each leaflet usually has an independent pulvinus at the base of the lamina, functioning as the motor organ for leaf movement. The determination of pulvinus identity in legumes seemingly shares a conserved genetic network orchestrated by a conserved LBD family gene, namely SLEEPLESS (SLP) in Lotus japonicas, APULVINIC $(A P U)$ in pea (P. sativum), and ELONGATED PETIOLULE1 (ELP1)/PETIOLULE-LIKE PULVINUS (PLP) in M. truncatula (Chen et al., 2012; Zhou et al., 2012). Mutations in these genes completely abolished the pulvinus development and leaf movement, while overexpression of ELP1/PLP in the 
M. truncatula elp1/plp mutants could not only rescue the pulvinus and movement defect but also lead to highly reduced petioles and rachises, distorted leaf blades, and dwarfed status in some cases, showing a phenotype partially similar to the $m t d w f 4 a$ mutants. Considering that the ELP1/PLP and its orthologs are highly homologous to the Arabidopsis LOB protein which has been shown to directly up-regulates the BR metabolic gene phyB Activation-tagged Suppressor1-dominant (BAS1), further efforts are needed to determine whether BR accumulation is involved in pulvinus development and what roles ELP1/PLP and its orthologs play in this process. The F-box protein MIO1/SLB1 is another factor necessary for robust pulvinus development (Zhou et al., 2021). The pulvini of miol/slb1 mutants were shortened even completely absent from the base of its leaflets, leading to a reduced degree of leaflet rotation or a completely impaired leaf movement. Therefore, an interesting and important question is how ELP1/PLP and MIO1/SLB1 control the pulvinus development of $M$. truncatula and whether there is a direct geneprotein relationship between $M I O 1 / S L B 1$ and $E L P 1 / P L P$, which awaits future elucidation.

In addition to the pulvinus playing a central role in leaf movement, other elements of the compound leaf, such as leaflet geometry (the spatial structure and organization of leaflets), would also play important roles, which is proposed recently. In the loss-of-function $m t d w f 4 a$ mutant, the shortened rachises and pulvini in leaves resulted in a physical space constraint among leaflets, leading to their leaflets could not close during the night in contrast to the wild-type (Zhao et al., 2021).

\section{CONCLUSION AND PERSPECTIVES}

As shown in the above sections, we now have a rather good knowledge of the genetic networks that control major developmental processes during the pattern formation of M. truncatula trifoliate leaves and that correspond to other morphological traits of the leaves. Briefly, one of the most critical developmental processes that determines the trifoliate leaf pattern is the formation of three separated leaflet primordia during early stages, which is characterized by two key events: the initiation of leaflet primordia and the boundary formation between leaflets; and the reported regulatory mechanisms involved in such biological events can be reasonably summarized into at least four aspects: (1) the LFY/SGL1 pathway plays a central role in maintaining the morphogenetic activity of the compound leaf primordia which determines the leaflet initiation from marginal regions of the leaf primordium (Figure 3A); (2) the leaflet initiation and outgrowth is tightly associated with the auxin pathway which is facilitated by multiple components, including MtYUCCA1-catalyzed auxin generation and MtPIN10-driven auxin redistribution (Figure 3B); (3) the boundary formation between leaflets is critically dependent on the function of the boundary-specific MtNAM/MtCUC2 gene and the FCL1 gene (Figure 3C); (4) the adaxial-abaxial polarity genes play important roles in determining the compound leaf pattern and there would be a complex crosstalk between the LFY/SGL1 pathway and the regulation of the adaxial-abaxial polarity (Figure 3D).
For a more comprehensive understanding of the molecular mechanism underlying the compound leaf pattern formation of $M$. truncatula, elucidation of the additional key players as well as of the coupled upstream and downstream pathways are required. Several important questions should be addressed in future studies such as the following. At first, the initiation of leaflet primordia and the boundary delimitation between them during pattern formation are two interconnected processes, and it will be important to investigate how they are coordinatively controlled. Secondly, FCL1 may be involved in regulating NAM/CUC transcription factor-dependent and/or auxindependent regulatory networks, and future investigation will be aimed at elucidating the mechanism of FCL1 controlling the leaf pattern formation. Thirdly, the adaxial-abaxial polarity genes MtREV1, MtPHAN, MtAGO7, and MtARF3 regulate both adaxial-abaxial identity and compound leaf patterning, and meanwhile, they were involved in the auxin signaling pathway, besides, PINNA1 shows an adaxial-specific expression pattern and is involved in the LFY/SGL1 pathway; therefore, complex links seem to exist between the establishment of adaxial-abaxial polarity, the auxin signaling pathway, and the LFY/SGL1 pathway during compound leaf patterning, and it would be promising to study such links at a deeper molecular level.

The genome sequences are now available for alfalfa, and CRISPR has been shown to efficiently work in it, which should greatly facilitate the translation of basic knowledge obtained in the $M$. truncatula to the future breeding of leaf traits in alfalfa (Chen et al., 2020; Shen et al., 2020). Most importantly, the loss-of-function mutant of MsPALM1 generated by CRISPR/Cas9 developed palmate-like pentafoliate leaves and besides, the mutated alleles and phenotypes can be stably transmitted to progenies by cross-pollination between two mutants in a transgene-free manner, which may help to accelerate the breeding speed.

\section{AUTHOR CONTRIBUTIONS}

XM wrote the first draft. LH and JC contributed to wrote and revised the manuscript. $\mathrm{LH}$ designed the figures. YL, DW, and BZ provided help and advice, and corrected the manuscript. All authors contributed to the article and approved the submitted version.

\section{FUNDING}

Work on leaf development in the Jianghua Chen lab is supported by the Strategic Priority Research Program of Chinese Academy of Sciences (Grant Nos. XDB27030106 and XDA26030301), CAS-Western Light "Cross-Team ProjectKey Laboratory Cooperative Research Project" (E1XB051), National Natural Science Foundation of China (U1702234 and 32170839, 31471171, and 32070204), the "High-end Scientific and Technological Talents in Yunnan Province" (2015HA032), and the Yunnan Fundamental Research Project (202101AW070004). 


\section{REFERENCES}

Adenot, X., Elmayan, T., Lauressergues, D., Boutet, S., Bouche, N., Gasciolli, V., et al. (2006). DRB4-dependent TAS3 trans-acting siRNAs control leaf morphology through AGO7. Curr. Biol. 16, 927-932. doi: 10.1016/j.cub.2006. 03.035

Aida, M., Ishida, T., Fukaki, H., Fujisawa, H., and Tasaka, M. (1997). Genes involved in organ separation in Arabidopsis: an analysis of the cup-shaped cotyledon mutant. Plant Cell 9, 841-857. doi: 10.1105/tpc.9.6.841

Bajguz, A., Chmur, M., and Gruszka, D. (2020). Comprehensive overview of the brassinosteroid biosynthesis pathways: substrates, products, inhibitors, and connections. Front. Plant Sci. 11:1034. doi: 10.3389/fpls.2020.01034

Bar, M., and Ori, N. (2014). Leaf development and morphogenesis. Development $141,4219-4230$.

Bar, M., and Ori, N. (2015). Compound leaf development in model plant species. Curr. Opin. Plant Biol. 23, 61-69. doi: 10.1016/j.pbi.2014.10.007

Barkoulas, M., Hay, A., Kougioumoutzi, E., and Tsiantis, M. (2008). A developmental framework for dissected leaf formation in the Arabidopsis relative Cardamine hirsuta. Nat. Genet. 40, 1136-1141. doi: 10.1038/ ng.189

Berger, Y., Harpaz-Saad, S., Brand, A., Melnik, H., Sirding, N., Alvarez, J. P., et al. (2009). The NAC-domain transcription factor GOBLET specifies leaflet boundaries in compound tomato leaves. Development 136, 823-832. doi: 10. 1242/dev.031625

Bharathan, G., Goliber, T. E., Moore, C., Kessler, S., Pham, T., and Sinha, N. R. (2002). Homologies in leaf form inferred from KNOXI gene expression during development. Science 296, 1858-1860. doi: 10.1126/science.107 0343

Bilsborough, G. D., Runions, A., Barkoulas, M., Jenkins, H. W., Hasson, A., Galinha, C., et al. (2011). Model for the regulation of Arabidopsis thaliana leaf margin development. Proc. Natl. Acad. Sci. U.S.A. 108, 3424-3429.

Blein, T., Hasson, A., and Laufs, P. (2010). Leaf development: what it needs to be complex. Curr. Opin. Plant Biol. 13, 75-82. doi: 10.1016/j.pbi.2009.09.017

Blein, T., Pulido, A., Vialette-Guiraud, A., Nikovics, K., Morin, H., Hay, A., et al. (2008). A conserved molecular framework for compound leaf development. Science 322, 1835-1839. doi: 10.1126/science.1166168

Byrne, M. E., Barley, R., Curtis, M., Arroyo, J. M., Dunham, M., Hudson, A., et al. (2000). Asymmetric leaves1 mediates leaf patterning and stem cell function in Arabidopsis. Nature 408, 967-971. doi: 10.1038/35050091

Cao, X., Yang, H., Shang, C., Ma, S., Liu, L., and Cheng, J. (2019). The roles of auxin biosynthesis YUCCA gene family in plants. Int. J. Mol. Sci. 20:6343. doi: 10.3390/ijms20246343

Challa, K. R., Rath, M., Sharma, A. N., Bajpai, A. K., Davuluri, S., Acharya, K. K., et al. (2021). Active suppression of leaflet emergence as a mechanism of simple leaf development. Nat. Plants 7, 1264-1275. doi: 10.1038/s41477-021-0 0965-3

Champagne, C., and Sinha, N. (2004). Compound leaves: equal to the sum of their parts? Development 131, 4401-4412. doi: 10.1242/dev.01338

Champagne, C. E., Goliber, T. E., Wojciechowski, M. F., Mei, R. W., Townsley, B. T., Wang, K., et al. (2007). Compound leaf development and evolution in the legumes. Plant Cell 19, 3369-3378. doi: 10.1105/tpc.107.052886

Chen, H., Zeng, Y., Yang, Y., Huang, L., Tang, B., Zhang, H., et al. (2020). Alleleaware chromosome-level genome assembly and efficient transgene-free genome editing for the autotetraploid cultivated alfalfa. Nat. Commun. 11:2494. doi: 10.1038/s41467-020-16338-x

Chen, J. H., Moreau, C., Liu, Y., Kawaguchi, M., Hofer, J., Ellis, N., et al. (2012). Conserved genetic determinant of motor organ identity in Medicago truncatula and related legumes. Proc. Natl. Acad. Sci. U.S.A. 109, 11723-11728. doi: 10. 1073/pnas.1204566109

Chen, J. H., Yu, J. B., Ge, L. F., Wang, H. L., Berbel, A., Liu, Y., et al. (2010). Control of dissected leaf morphology by a Cys(2)His(2) zinc finger transcription factor in the model legume Medicago truncatula. Proc. Natl. Acad. Sci. U.S.A. 107, 10754-10759. doi: 10.1073/pnas.1003954107

Chen, R. (2018). Functional genomics and genetic control of compound leaf development in Medicago truncatula: an overview. Methods Mol. Biol. 1822, 197-203. doi: 10.1007/978-1-4939-8633-0_14

Chen, R. (2019). Compound leaf development in Medicago truncatula. Model Legume Medicago Truncatula 19, 154-172.
Cheng, X., Gou, X., Yin, H., Mysore, K. S., Li, J., and Wen, J. (2017). Functional characterisation of brassinosteroid receptor MtBRI1 in Medicago truncatula. Sci. Rep. 7:9327. doi: 10.1038/s41598-017-09297-9

Cheng, X. F., Peng, J. L., Ma, J. Y., Tang, Y. H., Chen, R. J., Mysore, K. S., et al. (2012). NO APICAL MERISTEM (MtNAM) regulates floral organ identity and lateral organ separation in Medicago truncatula. New Phytol. 195, 71-84.

Cheng, Y., Dai, X., and Zhao, Y. (2007). Auxin synthesized by the YUCCA flavin monooxygenases is essential for embryogenesis and leaf formation in Arabidopsis. Plant Cell 19, 2430-2439. doi: 10.1105/tpc.107.053009

Couzigou, J. M., Zhukov, V., Mondy, S., Abu el Heba, G., Cosson, V., Ellis, T. H. N., et al. (2012). NODULE ROOT and COCHLEATA maintain nodule development and are legume orthologs of Arabidopsis BLADE-ON-PETIOLE genes. Plant Cell 24, 4498-4510. doi: 10.1105/tpc.112.103747

Du, F., Guan, C. M., and Jiao, Y. L. (2018). Molecular mechanisms of leaf morphogenesis. Mol. Plant 11, 1117-1134. doi: 10.1016/j.molp.2018. 06.006

Efroni, I., Eshed, Y., and Lifschitz, E. (2010). Morphogenesis of simple and compound leaves: a critical review. Plant Cell 22, 1019-1032. doi: 10.1105/tpc. 109.073601

Emery, J. F., Floyd, S. K., Alvarez, J., Eshed, Y., Hawker, N. P., Izhaki, A., et al. (2003). Radial patterning of Arabidopsis shoots by class III HD-ZIP and KANADI genes. Curr. Biol. 13, 1768-1774. doi: 10.1016/j.cub.2003.09.035

Fukushima, K., and Hasebe, M. (2014). Adaxial-abaxial polarity: the developmental basis of leaf shape diversity. Genesis 52, 1-18. doi: 10.1002/dvg.22728

Furumizu, C., Alvarez, J. P., Sakakibara, K., and Bowman, J. L. (2015). Antagonistic roles for KNOX1 and KNOX2 genes in patterning the land plant body plan following an ancient gene duplication. PLoS Genet. 11:e1004980. doi: 10.1371/ journal.pgen.1004980

Furutani, M., Nakano, Y., and Tasaka, M. (2014). MAB4-induced auxin sink generates local auxin gradients in Arabidopsis organ formation. Proc. Natl. Acad. Sci. U.S.A. 111, 1198-1203. doi: 10.1073/pnas.1316109111

Garcia, D., Collier, S. A., Byrne, M. E., and Martienssen, R. A. (2006). Specification of leaf polarity in Arabidopsis via the trans-acting siRNA pathway. Curr. Biol. 16, 933-938. doi: 10.1016/j.cub.2006.03.064

Ge, L., Yu, J., Wang, H., Luth, D., Bai, G., Wang, K., et al. (2016). Increasing seed size and quality by manipulating BIG SEEDS1 in legume species. Proc. Natl. Acad. Sci. U.S.A. 113, 12414-12419. doi: 10.1073/pnas.1611763113

Ge, L. F., Peng, J. L., Berbel, A., Madueno, F., and Chen, R. J. (2014). Regulation of compound leaf development by PHANTASTICA in Medicago truncatula. Plant Physiol. 164, 216-228. doi: 10.1104/pp.113.229914

Goliber, T., Kessler, S., Chen, J. J., Bharathan, G., and Sinha, N. (1999). Genetic, molecular, and morphological analysis of compound leaf development. Curr. Top. Dev. Biol. 43, 259-290. doi: 10.1016/s0070-2153(08)60384-1

Gonzalez, N., Vanhaeren, H., and Inze, D. (2012). Leaf size control: complex coordination of cell division and expansion. Trends Plant Sci. 17, 332-340. doi: 10.1016/j.tplants.2012.02.003

Guo, S., Zhang, X., Bai, Q., Zhao, W., Fang, Y., Zhou, S., et al. (2020). Cloning and functional analysis of dwarf gene mini plant 1 (MNP1) in Medicago truncatula. Int. J. Mol. Sci. 21:4968. doi: 10.3390/ijms21144968

Ha, C. M., Jun, J. H., Nam, H. G., and Fletcher, J. C. (2007). BLADE-ON-PETIOLE1 and 2 control Arabidopsis lateral organ fate through regulation of LOB domain and adaxial-abaxial polarity genes. Plant Cell 19, 1809-1825. doi: 10.1105/tpc. 107.051938

Hake, S., Smith, H. M. S., Holtan, H., Magnani, E., Mele, G., and Ramirez, J. (2004). The role of knox genes in plant development. Annu. Rev. Cell Dev. Biol. 20, 125-151. doi: 10.1146/annurev.cellbio.20.031803.093824

Hareven, D., Gutfinger, T., Parnis, A., Eshed, Y., and Lifschitz, E. (1996). The making of a compound leaf: genetic manipulation of leaf architecture in tomato. Cell 84, 735-744.

Harrison, C. J., Corley, S. B., Moylan, E. C., Alexander, D. L., Scotland, R. W., and Langdale, J. A. (2005). Independent recruitment of a conserved developmental mechanism during leaf evolution. Nature 434, 509-514.

Hay, A., and Tsiantis, M. (2006). The genetic basis for differences in leaf form between Arabidopsis thaliana and its wild relative Cardamine hirsuta. Nat. Genet. 38, 942-947. doi: 10.1038/ng1835

He, L., Liu, Y., He, H., Liu, Y., Qi, J., Zhang, X., et al. (2020). A molecular framework underlying the compound leaf pattern of Medicago truncatula. Nat. Plants 6, 511-521. doi: 10.1038/s41477-020-0642-2 
Hepworth, S. R., and Pautot, V. A. (2015). Beyond the divide: boundaries for patterning and stem cell regulation in plants. Front. Plant Sci. 6:1052. doi: $10.3389 /$ fpls.2015.01052

Hofer, J., Turner, L., Hellens, R., Ambrose, M., Matthews, P., Michael, A., et al. (1997). UNIFOLIATA regulates leaf and flower morphogenesis in pea. Curr. Biol. 7, 581-587. doi: 10.1016/s0960-9822(06)00257-0

Hofer, J., Turner, L., Moreau, C., Ambrose, M., Isaac, P., Butcher, S., et al. (2009). Tendril-less regulates tendril formation in pea leaves. Plant Cell 21, 420-428. doi: 10.1105/tpc.108.064071

Hofer, J. M., and Noel Ellis, T. H. (2014). Developmental specialisations in the legume family. Curr. Opin. Plant Biol. 17, 153-158. doi: 10.1016/j.pbi.2013.11. 014

Hofer, J. M. I., and Ellis, T. H. N. (1998). The genetic control of patterning in pea leaves. Trends Plant Sci. 3, 439-444.

Hunter, C., Willmann, M. R., Wu, G., Yoshikawa, M., de la Luz Gutierrez-Nava, M., and Poethig, S. R. (2006). Trans-acting siRNA-mediated repression of ETTIN and ARF4 regulates heteroblasty in Arabidopsis. Development 133, 2973-2981. doi: $10.1242 /$ dev.02491

Israeli, A., Capua, Y., Shwartz, I., Tal, L., Meir, Z., Levy, M., et al. (2019). Multiple auxin-response regulators enable stability and variability in leaf development. Curr. Biol. 29, 1746.e5-1759.e5. doi: 10.1016/j.cub.2019.04.047

Israeli, A., Reed, J. W., and Ori, N. (2020). Genetic dissection of the auxin response network. Nat. Plants 6, 1082-1090. doi: 10.1038/s41477-020-0739-7

Jeong, S. C., Kim, J. H., and Bae, D. N. (2017). Genetic analysis of the Lf1 gene that controls leaflet number in soybean. Theor. Appl. Genet. 130, 1685-1692. doi: 10.1007/s00122-017-2918-0

Jiao, K., Li, X., Su, S., Guo, W., Guo, Y., Guan, Y., et al. (2019). Genetic control of compound leaf development in the mungbean (Vigna radiata L.). Hortic. Res. 6:23. doi: 10.1038/s41438-018-0088-0

Jiao, K. Y., Li, X., Guo, Y. F., Guan, Y. X., Guo, W., Luo, D., et al. (2019). Regulation of compound leaf development in mungbean (Vigna radiata L.) by CUP-SHAPED COTYLEDON/NO APICAL MERISTEM (CUC/NAM) gene. Planta 249, 765-774. doi: 10.1007/s00425-018-3038-z

Kessler, S., and Sinha, N. (2004). Shaping up: the genetic control of leaf shape. Curr. Opin. Plant Biol. 7, 65-72. doi: 10.1016/j.pbi.2003.11.002

Kierzkowski, D., Runions, A., Vuolo, F., Strauss, S., Lymbouridou, R., RoutierKierzkowska, A. L., et al. (2019). A growth-based framework for leaf shape development and diversity. Cell 177, 1405.

Kim, M., McCormick, S., Timmermans, M., and Sinha, N. (2003). The expression domain of PHANTASTICA determines leaflet placement in compound leaves (vol 424, pg 438, 2003). Nature 425, 102-102. doi: 10.1038/nature01820

Kimura, S., Koenig, D., Kang, J., Yoong, F. Y., and Sinha, N. (2008). Natural variation in leaf morphology results from mutation of a novel KNOX gene. Curr. Biol. 18, 672-677. doi: 10.1016/j.cub.2008.04.008

Koenig, D., and Sinha, N. (2010). Evolution of leaf shape: a pattern emerges. Curr. Top. Dev. Biol. 91, 169-183. doi: 10.1016/S0070-2153(10)91006-5

Kong, Y., Meng, Z., Wang, H., Wang, Y., Zhang, Y., Hong, L., et al. (2021). Brassinosteroid homeostasis is critical for the functionality of the Medicago truncatula pulvinus. Plant Physiol. 185, 1745-1763. doi: 10.1093/plphys/ kiab008

Lenhard, M., Bohnert, A., Jurgens, G., and Laux, T. (2001). Termination of stem cell maintenance in Arabidopsis floral meristems by interactions between WUSCHEL and AGAMOUS. Cell 105, 805-814. doi: 10.1016/s0092-8674(01) 00390-7

Li, J., and Chory, J. (1997). A putative leucine-rich repeat receptor kinase involved in brassinosteroid signal transduction. Cell 90, 929-938. doi: 10.1016/s0092$8674(00) 80357-8$

Li, W., Ma, Q., Yin, P., Wen, J., Pei, Y., Niu, L., et al. (2021). The GA 20oxidase encoding gene MSD1 controls the main stem elongation in Medicago truncatula. Front. Plant Sci. 12:709625. doi: 10.3389/fpls.2021.709625

Liu, X., Bourgault, R., Galli, M., Strable, J., Chen, Z., Feng, F., et al. (2021). The FUSED LEAVES1-ADHERENT1 regulatory module is required for maize cuticle development and organ separation. New Phytol. 229, 388-402. doi: 10. $1111 /$ nph.16837

Long, J. A., Moan, E. I., Medford, J. I., and Barton, M. K. (1996). A member of the KNOTTED class of homeodomain proteins encoded by the STM gene of Arabidopsis. Nature 379, 66-69. doi: 10.1038/379066a0
Magnani, E., and Hake, S. (2008). KNOX lost the OX: the Arabidopsis KNATM gene defines a novel class of KNOX transcriptional regulators missing the homeodomain. Plant Cell 20, 875-887. doi: 10.1105/tpc.108.05 8495

Manuela, D., and Xu, M. (2020). Patterning a leaf by establishing polarities. Front. Plant Sci. 11:568730. doi: 10.3389/fpls.2020.568730

McAdam, E. L., Meitzel, T., Quittenden, L. J., Davidson, S. E., Dalmais, M., Bendahmane, A. I., et al. (2017). Evidence that auxin is required for normal seed size and starch synthesis in pea. New Phytol. 216, 193-204. doi: 10.1111/ nph. 14690

McConnell, J. R., Emery, J., Eshed, Y., Bao, N., Bowman, J., and Barton, M. K. (2001). Role of PHABULOSA and PHAVOLUTA in determining radial patterning in shoots. Nature 411, 709-713. doi: 10.1038/35079635

Meng, Y., Liu, H., Wang, H., Liu, Y., Zhu, B., Wang, Z., et al. (2019). HEADLESS, a WUSCHEL homolog, uncovers novel aspects of shoot meristem regulation and leaf blade development in Medicago truncatula. J. Exp. Bot. 70, 149-163. doi: 10.1093/jxb/ery346

Milla, R. (2012). Compound leaves and the evolution of leaf size and display. Ideas Ecol. Evol. 5:4288.

Moreau, C., Hofer, J. M. I., Eleouet, M., Sinjushin, A., Ambrose, M., Skot, K., et al. (2018). Identification of Stipules reduced, a leaf morphology gene in pea (Pisum sativum). New Phytol. 220, 288-299. doi: 10.1111/nph.15286

Nakata, M., Matsumoto, N., Tsugeki, R., Rikirsch, E., Laux, T., and Okada, K. (2012). Roles of the middle domain-specific WUSCHEL-RELATED HOMEOBOX genes in early development of leaves in Arabidopsis. Plant Cell 24, 519-535. doi: 10.1105/tpc.111.092858

Ochando, I., Gonzalez-Reig, S., Ripoll, J. J., Vera, A., and Martinez-Laborda, A. (2008). Alteration of the shoot radial pattern in Arabidopsis thaliana by a gainof-function allele of the class III HD-Zip gene INCURVATA4. Int. J. Dev. Biol. 52, 953-961. doi: 10.1387/ijdb.072306io

Pekker, I., Alvarez, J. P., and Eshed, Y. (2005). Auxin response factors mediate Arabidopsis organ asymmetry via modulation of KANADI activity. Plant Cell 17, 2899-2910. doi: 10.1105/tpc.105.034876

Peng, J., Berbel, A., Madueno, F., and Chen, R. (2017). AUXIN RESPONSE FACTOR3 regulates compound leaf patterning by directly repressing PALMATE-LIKE PENTAFOLIATA1 expression in Medicago truncatula. Front. Plant Sci. 8:1630. doi: 10.3389/fpls.2017.01630

Peng, J., and Chen, R. (2011). Auxin efflux transporter MtPIN10 regulates compound leaf and flower development in Medicago truncatula. Plant Signal. Behav. 6, 1537-1544. doi: 10.4161/psb.6.10.17326

Peng, J. L., Yu, J. B., Wang, H. L., Guo, Y. Q., Li, G. M., Bai, G. H., et al. (2011). Regulation of compound leaf development in Medicago truncatula by fused compound Leaf1, a class M KNOX gene. Plant Cell 23, 3929-3943. doi: 10.1105/ tpc. 111.089128

Rast-Somssich, M. I., Broholm, S., Jenkins, H., Canales, C., Vlad, D., Kwantes, M., et al. (2015). Alternate wiring of a KNOXI genetic network underlies differences in leaf development of A. thaliana and C. hirsuta. Gene Dev. 29, 2391-2404.

Rhoades, M. W., Reinhart, B. J., Lim, L. P., Burge, C. B., Bartel, B., and Bartel, D. P. (2002). Prediction of plant microRNA targets. Cell 110, 513-520.

Rong, F. X., Chen, F. F., Huang, L., Zhang, J. Y., Zhang, C. W., Hou, D., et al. (2019). A mutation in class III homeodomain-leucine zipper (HD-ZIP III) transcription factor results in curly leaf (cul) in cucumber (Cucumis sativus L.). Theor. Appl. Genet. 132, 113-123. doi: 10.1007/s00122-018-3198-z

Sayou, C., Monniaux, M., Nanao, M. H., Moyroud, E., Brockington, S. F., Thevenon, E., et al. (2014). A promiscuous intermediate underlies the evolution of LEAFY DNA binding specificity. Science 343, 645-648. doi: 10.1126/science. 1248229

Schmerler, S. B., Clement, W. L., Beaulieu, J. M., Chatelet, D. S., Sack, L., Donoghue, M. J., et al. (2012). Evolution of leaf form correlates with tropical-temperate transitions in Viburnum (Adoxaceae). Proc. Biol. Sci. 279, 3905-3913. doi: 10. 1098/rspb.2012.1110

Schoof, H., Lenhard, M., Haecker, A., Mayer, K. F. X., Jurgens, G., and Laux, T. (2000). The stem cell population of Arabidopsis shoot meristems is maintained by a regulatory loop between the CLAVATA and WUSCHEL genes. Cell 100, 635-644. doi: 10.1016/s0092-8674(00)80700-x

Shen, C., Du, H., Chen, Z., Lu, H., Zhu, F., Chen, H., et al. (2020). The chromosome-level genome sequence of the autotetraploid alfalfa and 
resequencing of core germplasms provide genomic resources for alfalfa research. Mol. Plant 13, 1250-1261. doi: 10.1016/j.molp.2020.07.003

Siegfried, K. R., Eshed, Y., Baum, S. F., Otsuga, D., Drews, G. N., and Bowman, J. L. (1999). Members of the YABBY gene family specify abaxial cell fate in Arabidopsis. Development 126, 4117-4128. doi: 10.1242/dev.126.18.4117

Sprent, J. I. (2007). Evolving ideas of legume evolution and diversity: a taxonomic perspective on the occurrence of nodulation. New Phytol. 174, 11-25. doi: 10.1111/j.1469-8137.2007.02015.x

Sprent, J. I. (2008). 60Ma of legume nodulation. What's new? What's changing? J. Exp. Bot. 59, 1081-1084. doi: 10.1093/jxb/erm286

Tadege, M., Lin, H., Bedair, M., Berbel, A., Wen, J. Q., Rojas, C. M., et al. (2011). STENOFOLIA regulates blade outgrowth and leaf vascular patterning in Medicago truncatula and Nicotiana sylvestris. Plant Cell 23, 2125-2142. doi: $10.1105 /$ tpc. 111.085340

Tang, G., Reinhart, B. J., Bartel, D. P., and Zamore, P. D. (2003). A biochemical framework for RNA silencing in plants. Genes Dev. 17, 49-63. doi: 10.1101/gad. 1048103

Tattersall, A. D., Turner, L., Knox, M. R., Ambrose, M. J., Ellis, T. H. N., and Hofer, J. M. I. (2005). The mutant crispa reveals multiple roles for PHANTASTICA in pea compound leaf development. Plant Cell 17, 1046-1060. doi: 10.1105/tpc. 104.029447

Timmermans, M. C. P., Hudson, A., Becraft, P. W., and Nelson, T. (1999). ROUGH SHEATH2: a Myb protein that represses knox homeobox genes in maize lateral organ primordia. Science 284, 151-153. doi: 10.1126/science.284.5411.151

Vandenbussche, M. (2021). The role of WOX1 genes in blade development and beyond. J. Exp. Bot. 72, 1514-1516. doi: 10.1093/jxb/eraa599

Vandenbussche, M., Horstman, A., Zethof, J., Koes, R., Rijpkema, A. S., and Gerats, T. (2009). Differential recruitment of WOX transcription factors for lateral development and organ fusion in Petunia and Arabidopsis. Plant Cell 21, 2269-2283. doi: $10.1105 /$ tpc. 109.065862

Verdeil, J. L., Alemanno, L., Niemenak, N., and Tranbarger, T. J. (2007). Pluripotent versus totipotent plant stem cells: dependence versus autonomy Trends Plant Sci. 12, 245-252. doi: 10.1016/j.tplants.2007.04.002

Vernoux, T., Besnard, F., and Godin, C. (2021). What shoots can teach about theories of plant form. Nat. Plants 7, 716-724. doi: 10.1038/s41477-021-009300

Vlad, D., Kierzkowski, D., Rast, M. I., Vuolo, F., Dello Ioio, R., Galinha, C., et al. (2014). Leaf shape evolution through duplication, regulatory diversification, and loss of a homeobox gene. Science 343, 780-783.

Vollbrecht, E., Veit, B., Sinha, N., and Hake, S. (1991). The developmental gene knotted-1 is a member of a maize homeobox gene family. Nature 350, 241-243. doi: 10.1038/350241a0

Waites, R., Selvadurai, H. R. N., Oliver, I. R., and Hudson, A. (1998). The PHANTASTICA gene encodes a MYB transcription factor involved in growth and dorsoventrality of lateral organs in Antirrhinum. Cell 93, 779-789. doi: 10.1016/s0092-8674(00)81439-7

Wang, C., Zhao, B., He, L., Zhou, S., Liu, Y., Zhao, W., et al. (2021). The WOX family transcriptional regulator SILAM1 controls compound leaf and floral organ development in Solanum lycopersicum. J. Exp. Bot. 72, 1822-1835. doi: $10.1093 / \mathrm{jxb} / \mathrm{eraa} 574$

Wang, H., Chen, J., Wen, J., Tadege, M., Li, G., Liu, Y., et al. (2008). Control of compound leaf development by FLORICAULA/LEAFY ortholog SINGLE LEAFLET1 in Medicago truncatula. Plant Physiol. 146, 1759-1772. doi: 10.1104/ pp.108.117044

Wang, H., Kong, F., and Zhou, C. (2021). From genes to networks: the genetic control of leaf development. J. Integr. Plant Biol. 63, 1181-1196. doi: 10.1111/ jipb. 13084

Wang, H., Xu, Y., Hong, L., Zhang, X., Wang, X., Zhang, J., et al. (2019). HEADLESS regulates auxin response and compound leaf morphogenesis in Medicago truncatula. Front. Plant Sci. 10:1024. doi: 10.3389/fpls.2019.01024

Wang, X., Zhang, J., Xie, Y., Liu, X., Wen, L., Wang, H., et al. (2021). LATE MERISTEM IDENTITY1 regulates leaf margin development via the auxin transporter gene SMOOTH LEAF MARGIN1. Plant Physiol. 187, 218-235. doi: 10.1093/plphys/kiab268

Wang, Y., and Chen, R. (2013). Regulation of compound leaf development. Plants $3,1-17$.

Wang, Y., and Jiao, Y. (2020). Keeping leaves in shape. Nat. Plants 6, 436-437. doi: 10.1038/s41477-020-0660-0
Wang, Z. H., Chen, J. H., Weng, L., Li, X., Cao, X. L., Hu, X. H., et al. (2013). Multiple components are integrated to determine leaf complexity in Lotus japonicus. J. Integr. Plant Biol. 55, 419-433. doi: 10.1111/jipb.12034

Warman, L., Moles, A. T., and Edwards, W. (2011). Not so simple after all: searching for ecological advantages of compound leaves. Oikos 120, 813-821.

Wen, L. Z., Kong, Y. M., Wang, H. F., Xu, Y. T., Lu, Z. C., Zhang, J., et al. (2021). Interaction between the MtDELLA-MtGAF1 complex and MtARF3 mediates transcriptional control of MtGA3ox1 to elaborate leaf margin formation in Medicago truncatula. Plant Cell Physiol. 62, 321-333. doi: 10.1093/pcp/pcaa163

Wisniewska, J., Xu, J., Seifertova, D., Brewer, P. B., Ruzicka, K., Blilou, I., et al. (2006). Polar PIN localization directs auxin flow in plants. Science 312:883. doi: $10.1126 /$ science. 1121356

Wolabu, T. W., Wang, H., Tadesse, D., Zhang, F., Behzadirad, M., Tvorogova, V. E., et al. (2021). WOX9 functions antagonistic to STF and LAM1 to regulate leaf blade expansion in Medicago truncatula and Nicotiana sylvestris. New Phytol. 229, 1582-1597. doi: 10.1111/nph.16934

Xiong, Y. Y., and Jiao, Y. L. (2019). The diverse roles of auxin in regulating leaf development. Plants Basel 8:243. doi: 10.3390/plants8070243

Yang, T., Li, Y., Liu, Y., He, L., Liu, A., Wen, J., et al. (2021). The 3-ketoacylCoA synthase WFL is involved in lateral organ development and cuticular wax synthesis in Medicago truncatula. Plant Mol. Biol. 105, 193-204. doi: 10.1007/ s11103-020-01080-1

Yin, P., Ma, Q., Wang, H., Feng, D., Wang, X., Pei, Y., et al. (2020). SMALL LEAF AND BUSHY1 controls organ size and lateral branching by modulating the stability of BIG SEEDS1 in Medicago truncatula. New Phytol 226, 1399-1412.

Yruela, I. (2015). Plant development regulation: overview and perspectives. J. Plant Physiol. 182, 62-78. doi: 10.1016/j.jplph.2015.05.006

Zadnikova, P., and Simon, R. (2014). How boundaries control plant development. Curr. Opin. Plant Biol. 17, 116-125. doi: 10.1016/j.pbi.2013.11.013

Zhang, F., Wang, Y. W., Li, G. F., Tang, Y. H., Kramer, E. M., and Tadege, M. (2014). STENOFOLIA recruits TOPLESS to repress ASYMMETRIC LEAVES2 at the leaf margin and promote leaf blade outgrowth in Medicago truncatula. Plant Cell 26, 650-664. doi: 10.1105/tpc.113.121947

Zhang, T., Li, Y., Ma, L., Sang, X., Ling, Y., Wang, Y., et al. (2017). LATERAL FLORET 1 induced the three-florets spikelet in rice. Proc. Natl. Acad. Sci. U.S.A. 114, 9984-9989. doi: 10.1073/pnas.1700504114

Zhang, T., You, J., Zhang, Y., Yao, W., Chen, W., Duan, Q., et al. (2021). LF1 regulates the lateral organs polarity development in rice. New Phytol. 231, 1265-1277. doi: 10.1111/nph.17220

Zhang, X. J., He, L. L., Zhao, B. L., Zhou, S. L., Li, Y. H., He, H., et al. (2020). Dwarf and Increased Branching 1 controls plant height and axillary bud outgrowth in Medicago truncatula. J. Exp. Bot. 71, 6355-6365. doi: 10.1093/jxb/eraa364

Zhao, B., He, L., Jiang, C., Liu, Y., He, H., Bai, Q., et al. (2020). Lateral leaflet suppression 1 (LLS1), encoding the MtYUCCA1 protein, regulates lateral leaflet development in Medicago truncatula. New Phytol. 227, 613-628. doi: 10.1111/ nph.16539

Zhao, W., Bai, Q., Zhao, B., Wu, Q., Wang, C., Liu, Y., et al. (2021). The geometry of the compound leaf plays a significant role in the leaf movement of Medicago truncatula modulated by mtdwarf4a. New Phytol. 230, 475-484. doi: 10.1111/ nph.17198

Zhao, Y., Liu, R., Xu, Y. T., Wang, M. M., Zhang, J., Bai, M. Y., et al. (2019). AGLF provides C-function in floral organ identity through transcriptional regulation of AGAMOUS in Medicago truncatula. Proc. Natl. Acad. Sci. U.S.A. 116, 5176-5181. doi: 10.1073/pnas. 1820468116

Zhao, Y. D., Christensen, S. K., Fankhauser, C., Cashman, J. R., Cohen, J. D., Weigel, D., et al. (2001). A role for flavin monooxygenase-like enzymes in auxin biosynthesis. Science 291, 306-309. doi: 10.1126/science.291.5502.306

Zhou, C., Han, L., Fu, C., Wen, J., Cheng, X., Nakashima, J., et al. (2013). The transacting short interfering RNA3 pathway and no apical meristem antagonistically regulate leaf margin development and lateral organ separation, as revealed by analysis of an argonaute7/lobed leaflet1 mutant in Medicago truncatula. Plant Cell 25, 4845-4862. doi: 10.1105/tpc.113.117788

Zhou, C., Han, L., Li, G., Chai, M., Fu, C., Cheng, X., et al. (2014). STM/BPlike KNOXI is uncoupled from ARP in the regulation of compound leaf development in Medicago truncatula. Plant Cell 26, 1464-1479. doi: 10.1105/ tpc. 114.123885

Zhou, C. N., Han, L., Fu, C. X., Chai, M. F., Zhang, W. Z., Li, G. F., et al. (2012). Identification and characterization of petiolule- like pulvinus 
mutants with abolished nyctinastic leaf movement in the model legume Medicago truncatula. New Phytol. 196, 92-100. doi: 10.1111/j.1469-8137.2012. 04268.x

Zhou, C. N., Han, L., Hou, C. Y., Metelli, A., Qi, L. Y., Tadege, M., et al. (2011). Developmental analysis of a Medicago truncatula smooth leaf margin1 mutant reveals context-dependent effects on compound leaf development. Plant Cell 23, 2106-2124. doi: 10.1105/tpc.111.085464

Zhou, C. N., Han, L., Zhao, Y., Wang, H. F., Nakashima, J., Tong, J. H., et al. (2019). Transforming compound leaf patterning by manipulating REVOLUTA in Medicago truncatula. Plant J. 100, 562-571. doi: 10.1111/tpj. 14469

Zhou, S., Yang, T., Mao, Y., Liu, Y., Guo, S., Wang, R., et al. (2021). The F-box protein MIO1/SLB1 regulates organ size and leaf movement in Medicago truncatula. J. Exp. Bot. 72, 2995-3011. doi: 10.1093/jxb/ erab033

Zhu, B. T., Li, H., Hou, Y. F., Zhang, P. C., Xia, X. Z., Wang, N., et al. (2019). AGAMOUS AND TERMINAL FLOWER controls floral organ identity and inflorescence development in Medicago truncatula. J. Integr. Plant Biol. 61, 917-923.

Zhang, J., Zhao, Y., Liu, R., Zhou, C., (2019). AGAMOUS-LIKE FLOWER regulates flower and compound leaf development through different regulatory mechanisms in Medicago truncatula. Plant Signaling. 14
Zhuang, L. L., Ambrose, M., Rameau, C., Weng, L., Yang, J., Hu, X. H., et al. (2012) LATHYROIDES, encoding a WUSCHEL-related Homeoboxl transcription factor, controls organ lateral growth, and regulates tendril and dorsal petal identities in garden pea (Pisum sativum L.). Mol. Plant 5, 1333-1345. doi: $10.1093 / \mathrm{mp} / \mathrm{sss} 067$

Conflict of Interest: The authors declare that the research was conducted in the absence of any commercial or financial relationships that could be construed as a potential conflict of interest.

Publisher's Note: All claims expressed in this article are solely those of the authors and do not necessarily represent those of their affiliated organizations, or those of the publisher, the editors and the reviewers. Any product that may be evaluated in this article, or claim that may be made by its manufacturer, is not guaranteed or endorsed by the publisher.

Copyright (c) $2022 \mathrm{Mo}, \mathrm{He}$, Liu, Wang, Zhao and Chen. This is an open-access article distributed under the terms of the Creative Commons Attribution License (CC BY). The use, distribution or reproduction in other forums is permitted, provided the original author(s) and the copyright owner(s) are credited and that the original publication in this journal is cited, in accordance with accepted academic practice. No use, distribution or reproduction is permitted which does not comply with these terms. 